RESEARCH

SERIES

NUMBER 97

November 2019

\section{RUGBY IN IRELAND: A STATISTICAL ANALYSIS OF PARTICIPATION \\ PETE LUNN AND ELISH KELLY}

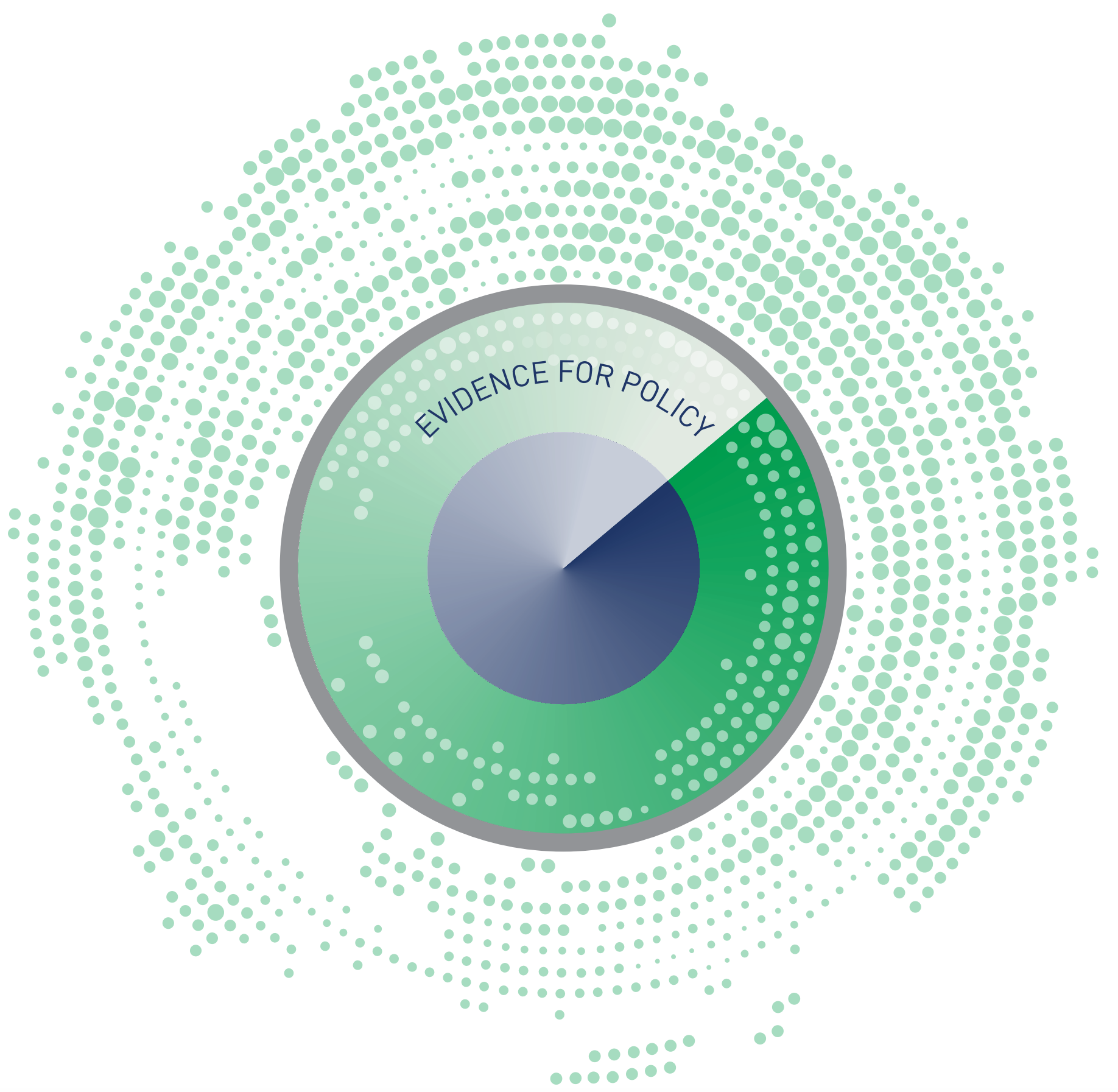




\title{
RUGBY IN IRELAND: A STATISTICAL ANALYSIS OF PARTICIPATION
}

\author{
Pete Lunn
}

Elish Kelly

\section{November 2019}

Available to download from www.esri.ie

(C) The Economic and Social Research Institute

Whitaker Square, Sir John Rogerson's Quay, Dublin 2

DOI: https://doi.org/10.26504/rs97.pdf

ISBN: 978-0-7070-0510-2

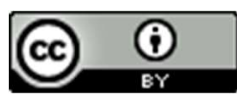

This Open Access work is licensed under a Creative Commons Attribution 4.0 International License (https://creativecommons.org/licenses/by/4.0/), which permits unrestricted use, distribution, and reproduction in any medium, provided the original work is properly credited. 


\section{ABOUT THE ESRI}

The mission of the Economic and Social Research Institute is to advance evidence-based policymaking that supports economic sustainability and social progress in Ireland. ESRI researchers apply the highest standards of academic excellence to challenges facing policymakers, focusing on 12 areas of critical importance to 21st century Ireland.

The Institute was founded in 1960 by a group of senior civil servants led by Dr T.K. Whitaker, who identified the need for independent and in-depth research analysis to provide a robust evidence base for policymaking in Ireland.

Since then, the Institute has remained committed to independent research and its work is free of any expressed ideology or political position. The Institute publishes all research reaching the appropriate academic standard, irrespective of its findings or who funds the research.

The quality of its research output is guaranteed by a rigorous peer review process. ESRI researchers are experts in their fields and are committed to producing work that meets the highest academic standards and practices.

The work of the Institute is disseminated widely in books, journal articles and reports. ESRI publications are available to download, free of charge, from its website. Additionally, ESRI staff communicate research findings at regular conferences and seminars.

The ESRI is a company limited by guarantee, answerable to its members and governed by a Council, comprising 14 members who represent a crosssection of ESRI members from academia, civil services, state agencies, businesses and civil society. The Institute receives an annual grant-in-aid from the Department of Public Expenditure and Reform to support the scientific and public interest elements of the Institute's activities; the grant accounted for an average of 30 per cent of the Institute's income over the lifetime of the last Research Strategy. The remaining funding comes from research programmes supported by government departments and agencies, public bodies and competitive research programmes.

Further information is available at www.esri.ie 


\section{THE AUTHORS}

Pete Lunn is an Associate Research Professor at the Economic and Social Research Institute (ESRI) and Elish Kelly is a Senior Research Officer at the ESRI. Both members of the research team hold adjunct research positions at Trinity College Dublin (TCD).

\section{ACKNOWLEDGEMENTS}

The authors would like to thank Scott Walker at the Irish Rugby Football Union (IRFU) for his commitment to generating and understanding objective statistical evidence. We are grateful to Sport Ireland for assistance in accessing data. We also thank the regional domestic rugby managers for feedback on initial results and drafts. We are grateful to audience members at IRFU seminars and committee meetings for helpful ideas and comments in relation to the results presented. We also thank Peter Smyth and Dr David Duffy for insightful comments on drafts. Any mistakes or omissions are our own. 


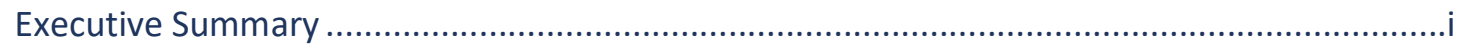

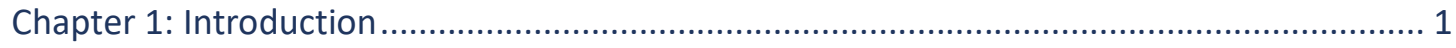

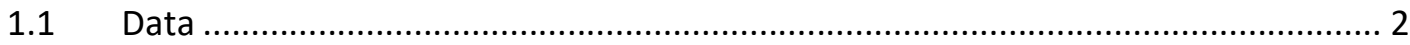

1.2 Demographic context and statistical methods...................................................... 5

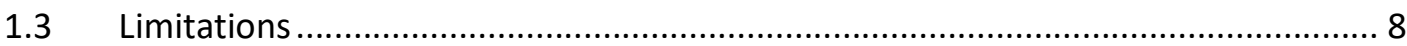

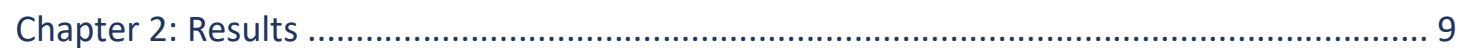

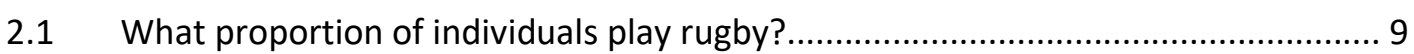

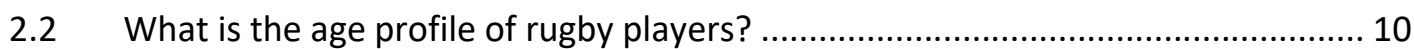

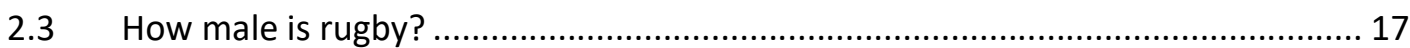

2.4 How strong is the socio-economic influence on playing rugby? ............................. 18

2.5 Does the pattern of participation vary by region? ................................................... 22

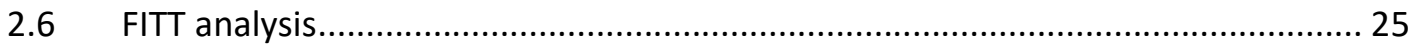

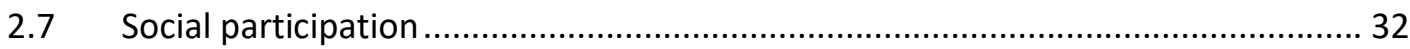

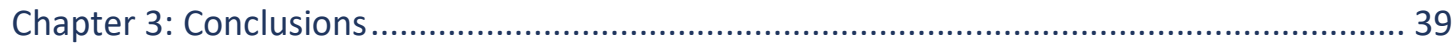

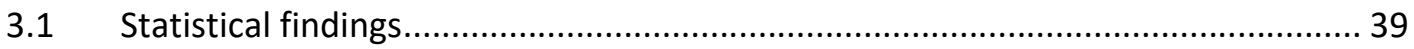

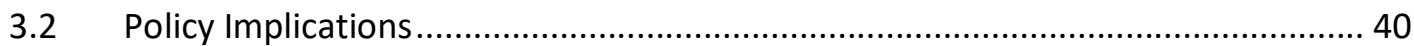

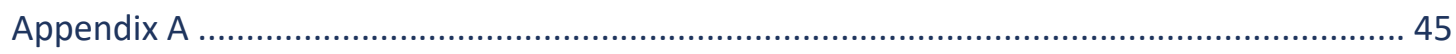

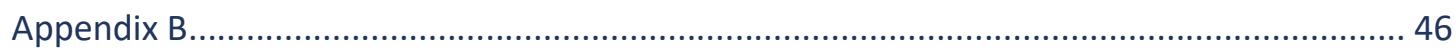

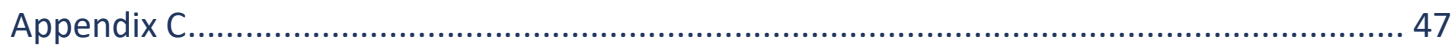

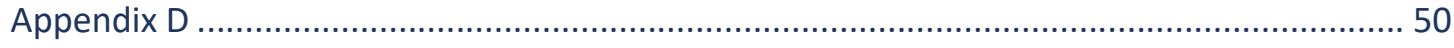

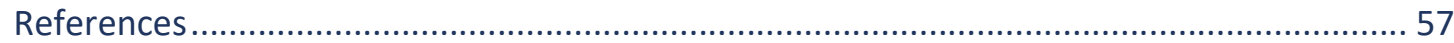




\section{LIST OF TABLES}

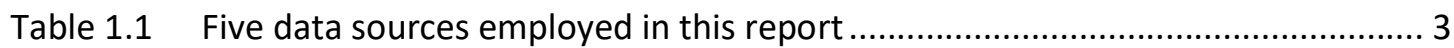

Table C1 Determinants of rugby participation in Rol: all (coefficients) ............................ 47

Table D1 Determinants of rugby membership in Rol: all (coefficients) ........................... 50

Table D2 Determinants of rugby attendance in Rol: all (coefficients) ............................... 53

\section{LIST OF FIGURES}

Figure 1.1 Population by individual year of age in 2016 (Rol) ..................................... 5

Figure 1.2 Population by individual year of age in 2011 (NI) ...................................... 6

Figure 2.1 Basic participation rates in rugby from five surveys ...................................... 9

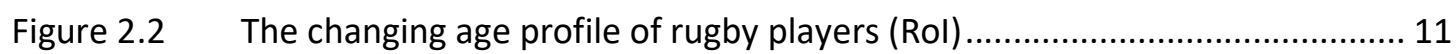

Figure 2.3 Age profile of adult rugby players by year (Rol) ........................................... 13

Figure 2.4 North-South comparison of the age profile of adult rugby players ............... 14

Figure 2.5 Comparison of age profiles of adult players of rugby, soccer, Gaelic football

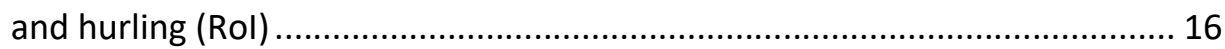

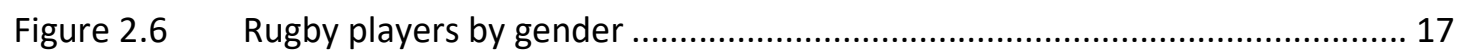

Figure 2.7 Odds ratios for adults playing rugby by educational attainment (Rol) .......... 20

Figure 2.8 Odds ratios for adults playing rugby by income (Rol) ................................... 21

Figure 2.9 Participation rate by region (Rol) ............................................................ 23

Figure 2.10 Regional comparison (Leinster and Munster only) of odds ratios for playing rugby by educational attainment (Rol) ......................................................... 24

Figure 2.11 Regional comparison of odds ratios for playing rugby by income (Rol) ......... 25

Figure 2.12 Motivations for active participation in team sports (Rol) ............................ 27

Figure 2.13 Frequency of active participation in rugby (Rol) ........................................ 28

Figure 2.14 Intensity of sessions of active participation in rugby (Rol) ............................. 29

Figure 2.15 Duration of sessions of active participation in rugby (Rol) ............................ 30

Figure 2.16 Context for active participation in rugby (Rol) .......................................... 31

Figure 2.17 Proportion of active participation in rugby accounted for by 'touch' or 'tag' rugby (Rol) ...................................................................................... 32

Figure 2.18 Social participation in rugby (Rol) ……................................................... 33

Figure 2.19 Comparison of active and social participation rates in rugby by gender (Rol) 34

Figure 2.20 Comparison of age profiles for active and social participation (Rol) .............. 35

Figure 2.21 Odds ratios for active and social participation in rugby by educational

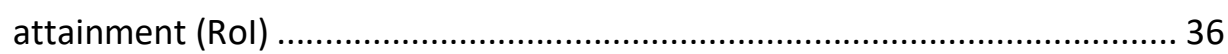

Figure 2.22 Odds ratios for active and social participation in rugby by household income

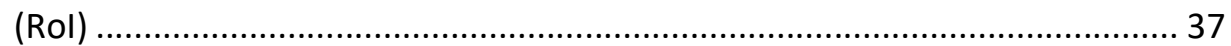




\section{ABBREVIATIONS}

CSPPA

FITT

ISM

SAPS

SLS

SSPE

TY
Children's Sport Participation and Physical Activity

frequency, intensity, time and type

Irish Sports Monitor

Sport and Physical Activity Survey

School Leavers' Survey

Survey of Sport and Physical Exercise

Transition Year 


\section{EXECUTIVE SUMMARY}

This report, commissioned by the Irish Rugby Football Union (IRFU), provides evidence relating to the level of participation in rugby in Ireland and the factors that underpin it. It exploits five data sources - four from the Republic of Ireland and one from Northern Ireland. The analysis investigates patterns of participation in rugby among adults and children, over time and by social group. It explores people's motivations for active participation and the extent of physical activity involved. In addition to active participation, i.e. physically playing rugby, patterns of social participation in the form of volunteering, club membership and attendance at events are analysed.

The primary purpose is to provide helpful evidence for the various organisations involved in managing and administering rugby in Ireland. Below we summarise some of the key findings and policy implications. Additional results, details and discussion of policy implications are given in the body of the report.

- Active participation in rugby has risen in recent decades among both adults and, especially, children.

- Just over 1 per cent of adults play regular rugby, but the figure is much higher among children, at more than 10 per cent of those aged under 13 years.

- Demographic change means that the number of children in Ireland is growing rapidly, presenting both a challenge and an opportunity for rugby.

- Children play rugby at clubs and at school, but many drop out when they move from primary to second level and when they leave secondlevel school.

- Rugby has a low drop-out rate among those who continue to play as adults, at least until their late twenties.

- Four out of five children who play rugby are male; nine out of ten adults who play are male.

- Playing rugby and social participation in rugby (club membership, attending fixtures, etc.) are strongly linked to socio-economic status.

- Students and people with higher educational attainment and higher income are much more likely to play rugby. 
- Participation in Munster, both active and social, is less confined to higher socio-economic groups and, probably as a consequence, is higher overall.

- The primary motivation for young adults playing team sports like rugby is the positive effect on their health and wellbeing.

- The frequency, intensity and duration of participation in rugby indicate that most players derive substantial health benefits from playing the game, provided they avoid serious injury.

- Touch and tag rugby accounts for just over 10 per cent of overall active participation, but a greater proportion among those aged over 25 years and among females.

- More people are rugby club members or regular spectators than play the game.

- Across all forms of the game, one-third of spectators at rugby matches are female.

\section{POLICY IMPLICATIONS}

- The primary challenge for policymakers trying to increase participation is not to entice more people to take up rugby, but to reduce drop-out.

- There is a need to increase the capacity of rugby clubs to cope with the increased number of young children in coming years.

- Keeping young rugby players involved when they change schools or leave school requires those running rugby to consider life beyond the game, tailoring rugby to fit increasingly busy lives and maintaining contact across transition periods.

- There is clear scope for further expansion of women's rugby.

- Rugby needs to reach out more to those in lower-socio-economic groups.

- Rugby clubs might look to provide opportunities for ongoing forms of physical activity for members and volunteers who no longer play 15-aside rugby. 


\section{CHAPTER 1}

\section{Introduction}

This report provides statistical evidence relating to the level of participation in rugby in Ireland and the factors that underpin it. In making use of five different representative data sources, including one from Northern Ireland, it is the most comprehensive such analysis undertaken to date for any specific sporting activity in Ireland. The picture that emerges is coherent. The datasets tell a consistent story of a sport that has increased in popularity in recent decades but faces some challenges, both at present and in the coming years. The primary aim of the report is to provide evidence to assist those involved in running rugby to identify and meet these challenges. The main research question is 'What determines whether individuals participate in rugby?', while the main policy implications focus on 'What might be done to increase participation?', including distinguishing between reducing drop-out and increasing takeup of the game.

Over recent decades, participation in sport has been recognised as an important aspect of public policy. Increasing participation has become an explicit policy goal in most developed countries, as a growing volume of evidence has linked levels of physical activity to prominent public health outcomes, including not only reduced incidence of disease but also mental health and wellbeing. This is indeed the case in Ireland, where raising levels of participation in sport and physical activity has been a stated policy goal for some years and forms a key part of the Department of Health's (2016) obesity policy and action plan (A Healthy Weight for Ireland). A substantial body of relevant research literature has accumulated internationally, with some contributions specific to Ireland. Although very little of this literature contains analyses that are specific to rugby, it forms an important part of the context for the current report. A summary (together with references) is therefore provided in Appendix A.

The primary aim of the main body of the report is to provide statistical evidence of potential use to the Irish Rugby Football Union (IRFU), but the goals of the report are broader than that. The results are intended to be of interest to schools, rugby clubs, volunteers, Local Sports Partnerships and national organisations with an interest in increasing participation in sport and physical activity. It is also hoped that the present project offers an indication of how quantitative research can contribute to our understanding of participation in specific sports and, therefore, assist efforts to increase participation. The report fits into a growing body of 
literature on patterns and determinants of participation in sport in Ireland. ${ }^{1}$

The report is organised into three sections. The remainder of this first section provides essential details about the data sources employed and methods used to analyse the data, while noting some limitations of the approach. Section 2 presents the results, with the primary research questions separated into subsections. While most of the focus is on active participation, i.e. playing rugby, Subsection 2.6 also provides evidence in relation to social participation in the form of volunteering, club membership and attendance at events. The emphasis in this main body of the report is on providing a quantitative statistical analysis that is readily understandable to the general reader who is not trained in multivariate statistical methods. The methods of data presentation have been selected with this goal in mind. Many of the results, however, are based on multivariate statistical models that may be of interest to those with statistical expertise. We provide a subset of this raw statistical output in the Appendices. Section 3 considers and discusses the policy implications of the findings.

\subsection{DATA}

Table 1.1 provides a summary of the five data sources employed, together with key information about the periods of data collection, survey sizes, populations surveyed, methods of data collection and the reference periods over which respondents were asked to recall their sporting activities. The first three datasets relate to adult participation, while the last two record children's participation. 


\begin{tabular}{|c|c|c|c|c|c|}
\hline Survey & Date & Sample & $\begin{array}{c}\text { Sampled } \\
\text { population }\end{array}$ & Method & $\begin{array}{l}\text { Reference } \\
\text { Period }\end{array}$ \\
\hline $\begin{array}{l}\text { Irish Sports Monitor } \\
\text { (ISM) }\end{array}$ & $\begin{array}{l}2007- \\
2017^{a}\end{array}$ & 61,541 & $16+$ years, Rol $^{b}$ & Telephone & 7 days \\
\hline $\begin{array}{l}\text { Sport and Physical } \\
\text { Activity Survey (SAPAS) }\end{array}$ & 2010 & 4,653 & $16+$ years, $\mathrm{NI}^{\mathrm{c}}$ & $\begin{array}{l}\text { Face to } \\
\text { face }\end{array}$ & 12 months \\
\hline $\begin{array}{l}\text { Survey of Sport and } \\
\text { Physical Exercise (SSPE) }\end{array}$ & 2003 & 3,080 & $18+$ years, Rol & $\begin{array}{l}\text { Face to } \\
\text { face }\end{array}$ & 12 months \\
\hline $\begin{array}{l}\text { Children's Sport } \\
\text { Participation and } \\
\text { Physical Activity } \\
\text { (CSPPA) }\end{array}$ & 2009 & $\begin{array}{l}1,275 \\
\text { and } \\
4,101\end{array}$ & $\begin{array}{l}\text { Primary and } \\
\text { second-level } \\
\text { students, Rol }\end{array}$ & In class & School year \\
\hline $\begin{array}{l}\text { School Leavers' Survey } \\
\text { (SLS) }\end{array}$ & 2007 & 2,025 & $\begin{array}{l}\text { Recent school } \\
\text { leavers, Rol }\end{array}$ & $\begin{array}{l}\text { Multi- } \\
\text { mode }\end{array}$ & $\begin{array}{l}\text { Second-level } \\
\text { school years }\end{array}$ \\
\hline
\end{tabular}

Note: $\quad{ }^{a}$ Data were collected only every other year after $2009 ;{ }^{b} \mathrm{RoI}=$ Republic of Ireland; ${ }^{c} \mathrm{NI}=$ Northern Ireland.

The largest and most detailed data source is the Irish Sports Monitor (ISM).

The present report makes extensive use of this survey, which was commissioned by the Irish Sports Council ${ }^{2}$ and designed specifically to monitor trends in sport and exercise in the Republic of Ireland. Data collection was by telephone survey throughout the year and respondents were asked to recall activities undertaken in the previous seven days. Data were collected in 2007, 2008, 2009, 2011, 2013, 2015 and 2017. By the standards of social surveys, the sample of over 65,000 is very large.

Since rugby is organised on an all-island basis, it is important to include data from Northern Ireland. The Sport and Physical Activity Survey (SAPAS) of 2010, conducted by Sport Northern Ireland, is the closest analogue to the ISM in that it asks comprehensive questions about sport and physical activity to a representative sample of adults. There are important differences in the wording of questions, the reference period and, especially, the sample size, which is an order of magnitude smaller than the ISM. Given this, many findings are reported here where the primary measure of statistical significance is taken from the ISM survey, but the results from the SAPAS survey are checked for compatibility. In general, as will be shown below, there is little reason to believe that patterns of 
participation in rugby are substantially different on either side of the border.

Limited use is made of the Survey of Sport and Physical Exercise (SSPE) from back in 2003, which was conducted by the Economic and Social Research Institute (ESRI) for the Irish Sports Council. This survey involved a very comprehensive and high-quality questionnaire, which included data on past regular participation in sport dating back over several decades. It therefore remains useful for setting current participation levels in a historical context.

Two data sources on children's participation are also employed, though unfortunately neither covers Northern Ireland. The 2009 Children's Sport Participation and Physical Activity (CSPPA) study used a nationally representative sample of 53 primary and 70 second-level schools, whose students completed questionnaires in their classes about their participation in sport and physical activity both inside and outside of school. Lastly, the School Leavers' Survey (SLS) of 2007 interviewed people two years after they had left school about their experiences of secondlevel school. This survey included questions about which sports the students had participated in at school and during which years.

The use of five different surveys that are representative of different populations brings both advantages and challenges. There are two main advantages. First, it offers the opportunity to exploit a rich array of questions and analyses. This means that there is a large and varied set of available survey questions with which to generate a quite detailed picture of participation. Second, where results prove to be consistent across survey instruments with different reference periods, question formats and data collection techniques (e.g. telephone and face to face), we can be confident in the findings.

The potential downside is that using multiple datasets raises the possibility that some findings may be inconsistent across them. If so, it may be unclear whether the inconsistency reflects different populations, time periods, nuances in the way survey questions are framed, sampling error, and so on. Given this, greater weight is placed throughout this report on results that are consistent across the surveys. In general, however, and rather comfortingly, we find little disagreement between the results from the different datasets and, in most instances, good agreement. Further details about the surveys used in this report are contained in a number of previous publications, which are described in Appendix B. 


\subsection{DEMOGRAPHIC CONTEXT AND STATISTICAL METHODS}

Irish demography provides an important part of the context for understanding the patterns of participation presented in this report. Figure 1.1 plots the number of people living in the Irish state by individual year of age (up to age 50) and gender, according to Census 2016. This chart makes plain the extraordinary difference in the size of successive cohorts that are less than a generation apart in age. The drop in numbers from those aged 36 years to those aged 23 years is fully 36 per cent. This pattern is the result of a combination of historical fertility trends and migration patterns during Ireland's boom and subsequent economic crisis. It is apparent for both genders. In recent years, however, the birth rate has risen as the large group in its early thirties has entered peak childbearing years. Hence, there is a substantial increase in the number of children, especially those aged four to ten years in 2016.

\section{FIGURE 1.1 POPULATION BY INDIVIDUAL YEAR OF AGE IN 2016 (ROI)}

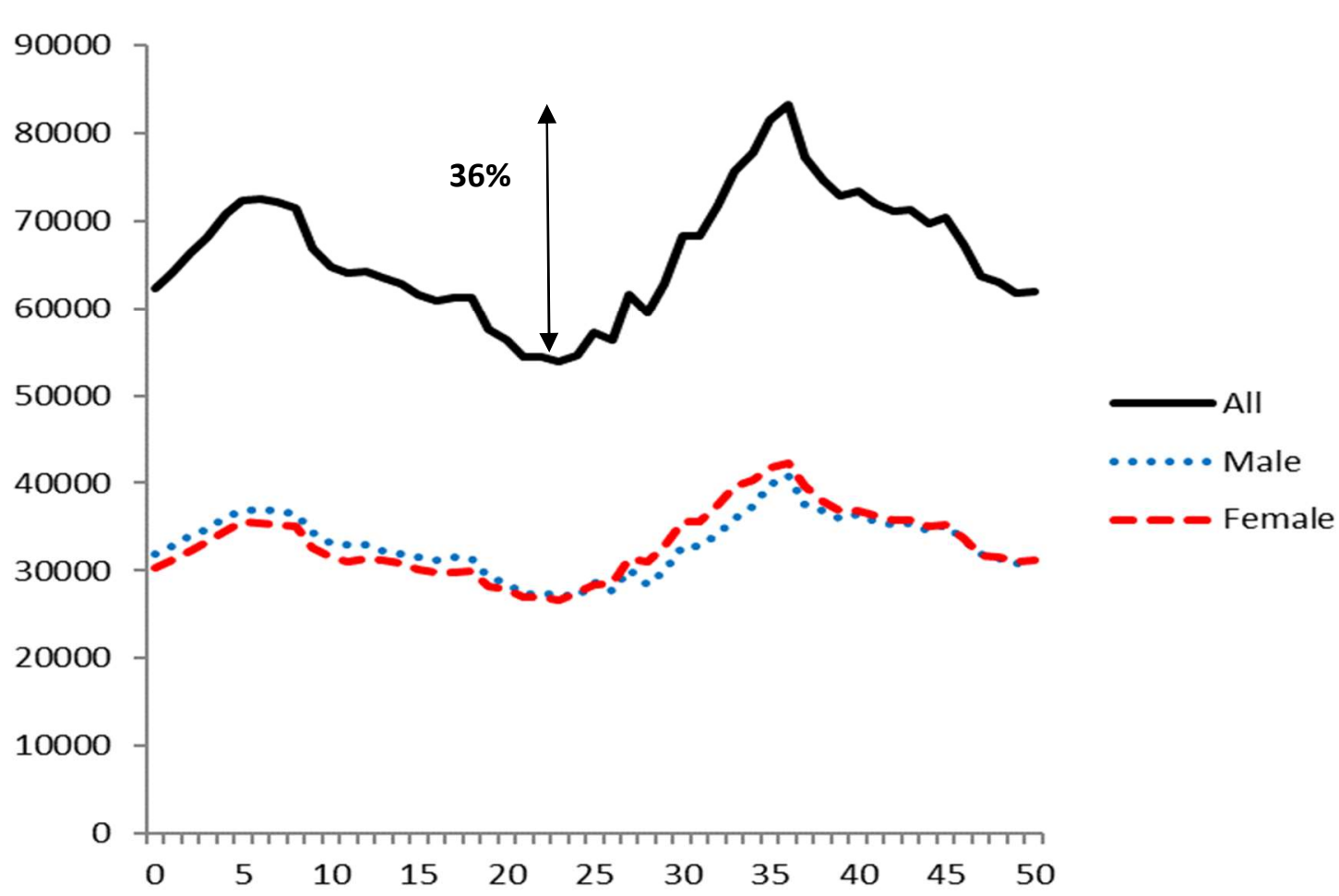

Source: Census 2016.

The demographic profile of Northern Ireland is different and is shown in Figure 1.2. The figure is based on the latest UK Census undertaken by the Office for National Statistics (ONS), which is for 2011. Again, there is variation in the size of successive cohorts, but its extent is considerably smaller and the largest variation occurs between cohorts aged 3-15 years. 
The smallest cohort was aged 8 years in 2011, after which the birth rate increased. Again, this pattern is common to both genders.

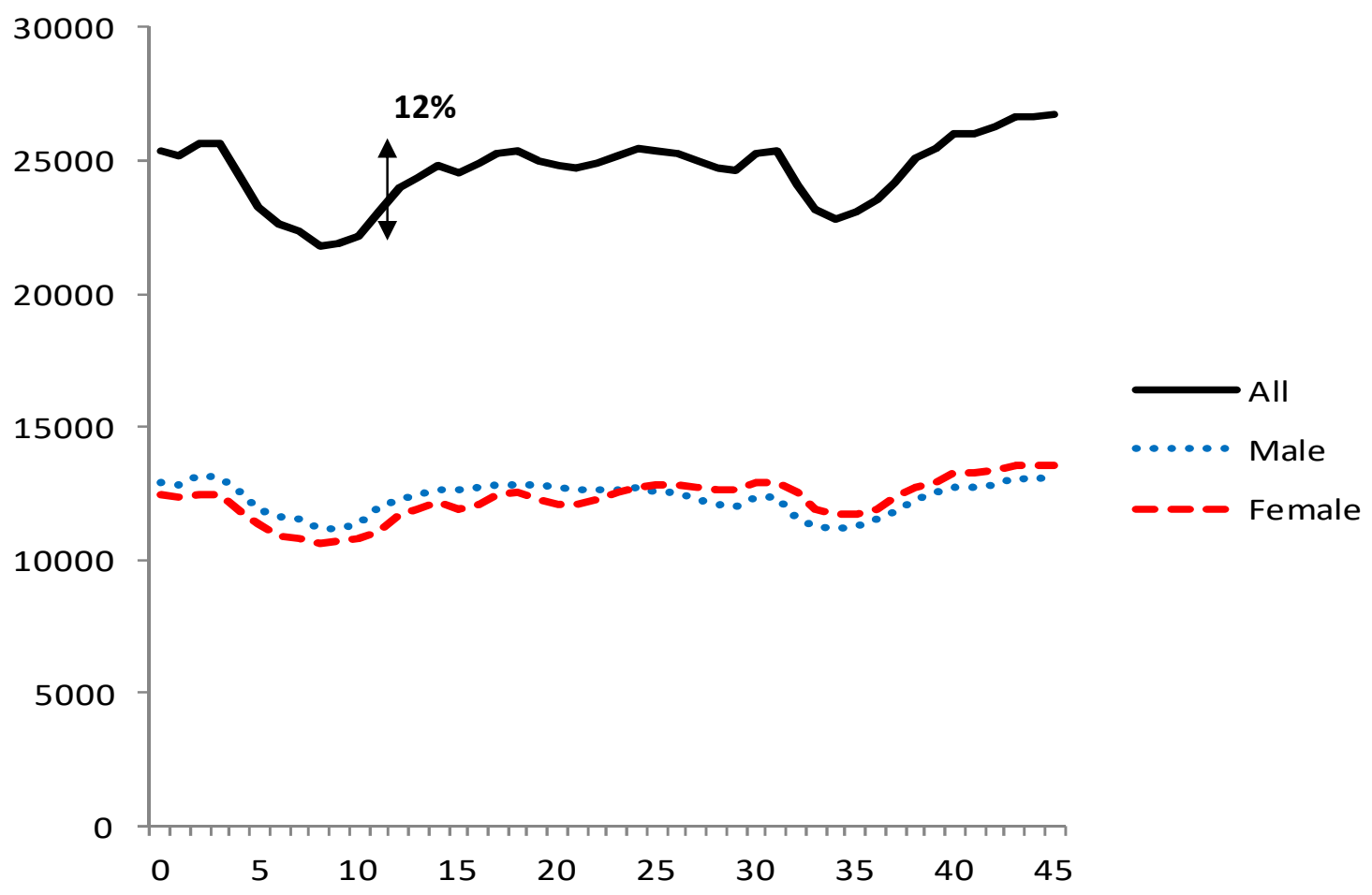

Source ONS, 2011.

These demographic figures are important for understanding patterns of participation in sport. It is highly likely that a contact team sport, which appeals most to younger people, will experience a decline in the numbers playing the game when its prime age group diminishes in size by such a large magnitude. While policies enacted by those running the game may have an impact on the likelihood that individuals take up or drop out from the sport, any such impact would have to be dramatic to trump the sort of changes in cohort size depicted above, especially in the Republic of Ireland.

The demographic profile helps to explain two apparently contradictory perceptions: that rugby has gained in popularity and that some rugby clubs are at present struggling to maintain the same number of teams as in previous years. The apparent contradiction is resolved if it is recognised that rugby may be more popular among the current cohort of young people than in previous years, but the size of this cohort is much smaller than its immediate predecessor. 
The variability in the demographic profiles also has implications for how the data in this report are presented. From the perspective of policies designed to increase participation, the most important figure is arguably the proportion of individuals within a given group that participates in the target activity. A good participation policy can increase this probability, improving the chance that an individual plays the sport; it cannot alter national demographics. Thus, the charts presented here mostly compare and contrast not participation numbers but participation rates, i.e. the percentage of members of a given group that participates in rugby, where the group might be defined by age, gender, socio-economic group, region and so on.

Reporting participation rates like this is more relevant for assessing policy, but can nevertheless be somewhat misleading. For example, young adults are much more likely to play rugby than older ones. Age clearly reduces the tendency to participate in such a vigorous contact sport. However, students are also more likely to play rugby than non-students, and students are also substantially more likely to be younger. So, is age or attachment to educational institutions the more crucial influence?

To answer such questions, we use multivariate statistical techniques (regression models) that estimate the individual impact of a given characteristic (gender, age, educational attainment, employment status, income, etc.) while simultaneously controlling for other background characteristics that can affect participation. Appendices $C$ and $D$ present the full results of two sets of statistical models, one for active participation, the other for social participation. Readers comfortable with interpreting such tables are invited to examine them, but it is important to understand that the results selected for presentation here and highlighted in the text are those that emerged as significant from the multivariate analyses. That is, it is ultimately the statistical models that underpin our analysis.

For those not versed in reading and interpreting such models, the key point is that not all of the differences in rates of participation in rugby that are apparent in the charts reflect statistically significant differences in the tendencies of different groups to participate. The main text aims to draw the reader's attention to the differences that are significant and to explain what might lie behind other differences that appear to be significant at first glance but are probably caused by a hidden factor, which our statistical models allow us to identify. 


\subsection{LIMITATIONS}

The primary aim of this report is to provide evidence for policies designed to increase the level of participation in rugby, either by increasing take-up of the sport by new participants or by reducing drop-out among those who already play. In this context, it is assumed throughout that participation in rugby is of net benefit to individuals who participate, as well as to the wider community of individuals and organisations that takes an interest in the sport. This is in line with the body of research literature on the link to health and wellbeing summarised in Appendix A. Moreover, some of the analysis below is suggestive of the likely health benefits that a large majority of participants derive from the physical activity involved.

Importantly, however, it is clear that playing rugby carries the risk of injury, including concussion and on rare occasions serious injury. ${ }^{3}$ No attempt is made in the current report to quantify this aspect of the game, which is beyond the methods and scope of the kind of survey research presented.

All statistical surveys are approximate. Measurement error may be caused by people who recall their activity inaccurately, respondents who wish to paint themselves in a good light, survey staff who fail to make contact with hard-to-reach groups, interviewers who record responses inaccurately, and so on. All participation rates therefore have margins of error and small differences should not be over-interpreted as meaningful. The statistical results presented in Appendices $C$ and $D$ employ techniques designed to ensure that the inferences drawn are given appropriate weight, while in the text emphasis is placed on results that are consistent across data sources or that correspond to large differences relative to plausible margins of error.

It is also almost always the case that surveys fail to capture some relevant information. In the present case, one difficulty is that the main survey questions of interest did not distinguish perfectly (or in some cases at all) between different types of participation in rugby. Most notably, only the ISM permits a comparison of participation in full-contact 15-a-side rugby and playing 'touch' or 'tag' rugby (see Subsection 2.5). In all other analyses, all forms of participation in rugby are included.

3 A vigorous academic debate on the issue of how policymakers should respond to injury risk in rugby arose in 2016. Space does not permit a detailed discussion here. Interested readers are referred to Tucker et al. (2016) and references therein. 


\section{CHAPTER 2}

\section{Results}

\subsection{WHAT PROPORTION OF INDIVIDUALS PLAY RUGBY?}

Figure 2.1 provides active participation rates for playing rugby for children and adults as recorded in the five surveys analysed for the current report (note the change of scale of the vertical axes). The left-hand panel reveals that almost 16 per cent of primary school children in fifth and sixth class play regular rugby during term time, either at school or in clubs. This rate declines to less than 10 per cent for second-level students. The SLS rate is lower than the rate for the CSPPA because the survey asked respondents only about participation in rugby at school, whereas the CSPPA captures rugby participation within and outside of the school (e.g. in rugby clubs). The comparison therefore amounts to an estimate of how much of the active participation of children in rugby takes place within and outside of school. In approximate terms, this seems to be close to a 50-50 split.

\section{FIGURE 2.1 BASIC PARTICIPATION RATES IN RUGBY FROM FIVE SURVEYS}
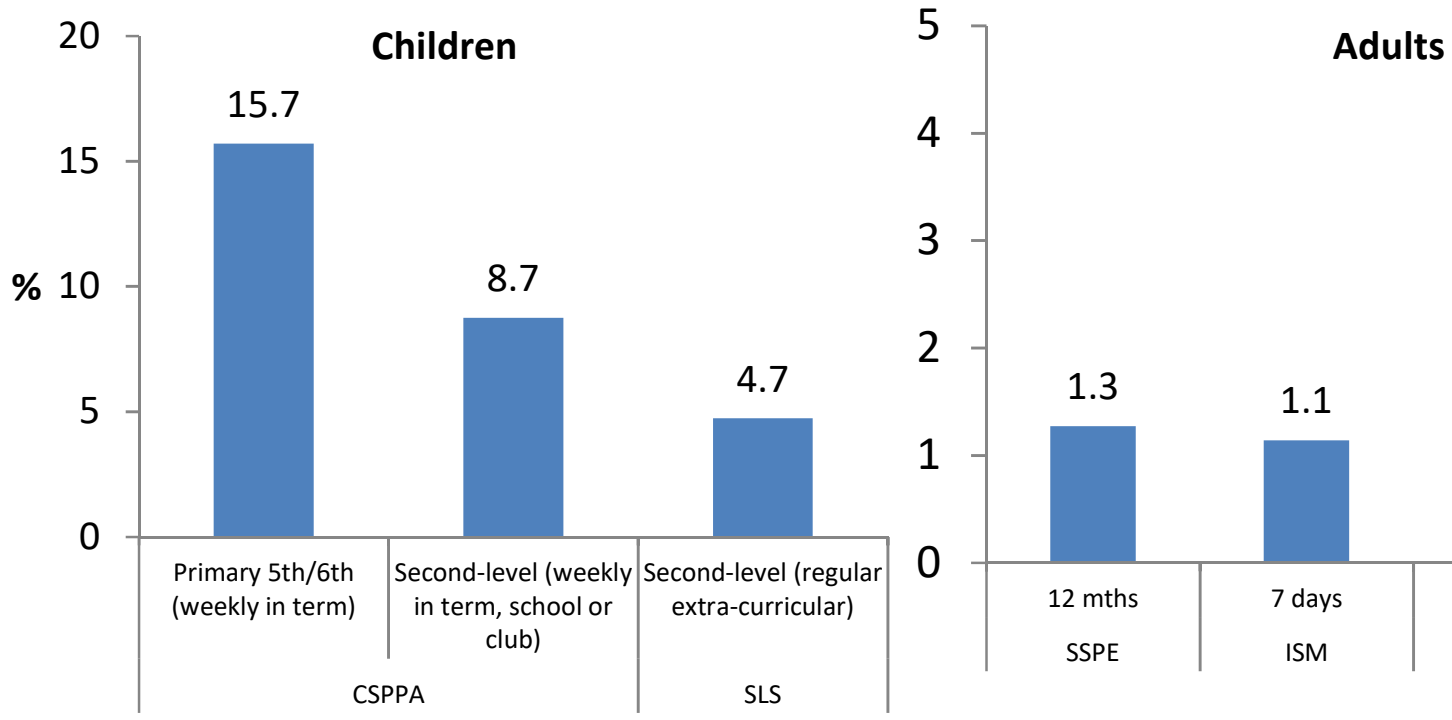

\section{7}

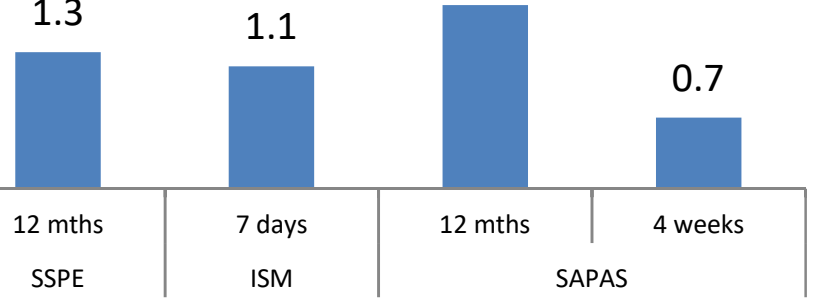

The right-hand panel indicates an active participation rate in rugby of just over 1 per cent of the adult population. It should be noted that it is generally difficult to measure proportions as low as 1-2 per cent accurately in surveys, despite the approximate agreement across surveys shown here. The ISM data are likely to be the most accurate of these measures, because of both that survey's sample size and the greater accuracy of its seven-day 
recall period. The figure of 1.1 per cent is the total figure from all the pooled ISM data from 2007 to 2013. If one considers that rugby is a seasonal sport, however, this figure will underestimate the number of regular rugby players in proportion to the months of the year during which they cease playing regularly, i.e. if players are assumed not to train or play for four months of the year, the figure for regular players during the season would equate to 1.6 per cent, or approximately 60,000 regular rugby players in the Republic of Ireland aged 16 and over. The sample and method of SAPAS does not permit derivation of an equivalent figure for Northern Ireland. Lastly, looking across the datasets as a whole, although the figures hint at an underlying increase in the active participation rate over time, there is not a clear and statistically significant trend that can be identified.

Overall, these figures place rugby among the dozen or so most popular sports in Ireland, but participation remains well short of the most popular sports. Among children, these are soccer, swimming and Gaelic games, while among adults the most popular during this recent time period were soccer, swimming, personal exercise and golf.

\subsection{WHAT IS THE AGE PROFILE OF RUGBY PLAYERS?}

All five datasets contain information on the individual year of age of rugby players, albeit with somewhat varying definitions of participation and recorded at different life stages. This section presents the results of an effort to piece this information together in order to obtain insights into when in the life-course individuals are most likely to take up rugby and when they are most likely to drop out. Figure 2.2 charts five separate age profiles from four of the surveys. No data is available for children prior to 5th and 6th class at primary school. This chart contains a wealth of useful information and so time is taken here to describe it in detail.

A first point to notice about this chart is the close correspondence between the estimated participation rates recorded by the ISM and the CSPPA (filled black and dark grey circles respectively). Despite the different sample populations, sampling techniques and questionnaires, the two age profiles join almost perfectly. These data represent the most accurate assessment we have of the present age profile of rugby players in Ireland. The clear indication is that a substantial proportion of modern Irish children participate in what would be 'mini-rugby' by around 12 years of age. The problem for those seeking to raise the level of participation in rugby, therefore, is primarily not one of attracting individuals to the game, but of keeping them playing the game. There are two distinct periods during 
which large proportions of players drop out: following the transition from primary to second-level school and following the completion of secondlevel school.

It is important to understand, however, that the declining age profile presented probably in part represents a 'cohort effect' rather than an 'age effect'. That is, if there has been substantial growth in mini-rugby in recent years, then the cohort at present in their twenties or later teenage years may never have had the level of participation recorded in Figure 2.2 for 12 year-olds. Moreover, it is possible that the group corresponding to the 12year-olds in this chart will in fact go on to record higher participation rates in rugby as adolescents and adults compared to the current cohorts at those ages, simply because more of them play at age 12 , regardless of any changes in the way the sport is organised.

\section{FIGURE 2.2 THE CHANGING AGE PROFILE OF RUGBY PLAYERS (ROI)}

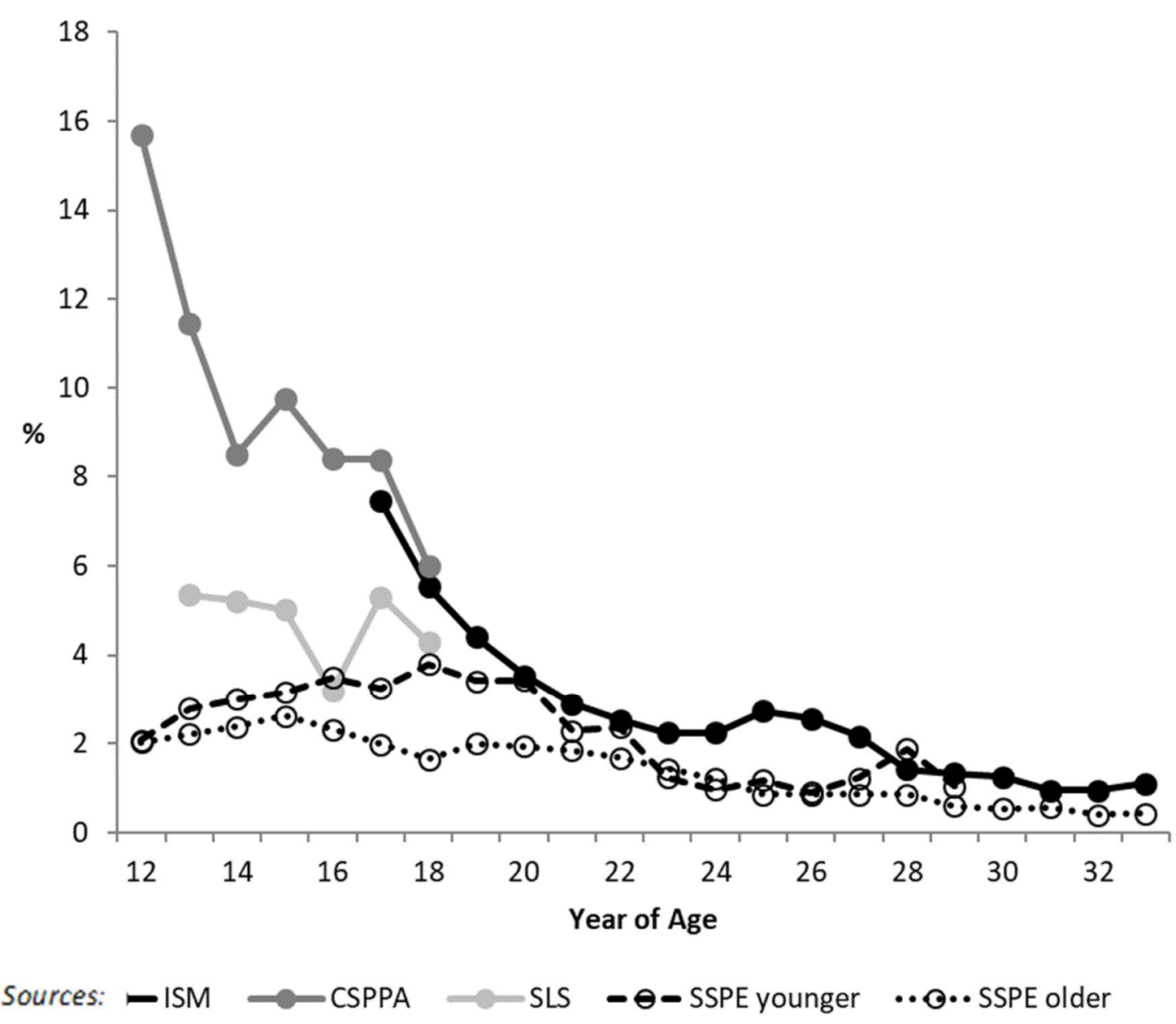


The two broken lines in the chart are important in this regard and require some attention. These figures are derived from a statistical reconstruction of Irish sport undertaken using the comprehensive 2003 SSPE. These data have previously been used successfully to match trends in participation rates in a number of sports from several decades ago up to the present date. The survey asked respondents to recall which sport and exercise activities they used to participate in regularly, what age they started each activity and when they stopped. The figures correspond to the responses given with respect to rugby by two different cohorts of adults: a 'younger' cohort aged 18-29 years in 2003 and an 'older' cohort aged 30-49 years in 2003. As is clear from the age profiles of past participation for these adult cohorts, there has been a dramatic expansion of rugby among children, especially younger children, in recent years. The suggestion of the gap between the two broken lines in Figure 2.2 is that this growth began at least as far back as the late 1980s and early 1990s, when the 'younger' group were in their teenage years. Since then, however, the growth has been much stronger, as revealed by the comparison between the broken lines and the dark grey line.

The final line deserving of attention in Figure 2.2 is the light grey one, which corresponds to the participation rate recorded by the SLS. At the age that would correspond to Transition Year (TY) for many second-level students, there is a noticeable dip in participation in extracurricular rugby played at school (this dip is evident among males and, therefore, is not merely reflective of the gender profile of TY students). More generally, however, both children's surveys indicate that the participation rate during the second-level school years holds up pretty well - it is what happens at the beginning and end of these years that seems to matter more.

It seems clear overall that modern children are far more likely to take up rugby than children in previous generations. Nevertheless, such differences between successive cohorts cannot explain the large differences in participation rates recorded above between those aged 12 years and those aged 14 years, nor between those aged 17 years and those aged 20 years. The differences involved are simply too large and take place over too few years. The strong suggestion is that individuals are particularly likely to drop out from rugby when they transition from primary to second-level school and, even more so, when they leave second-level school. Participation approximately halves at the first of these transition points and more than halves at the second. Note that this does not necessarily imply that they were playing the sport at school - these transition points involve multiple changes in people's lives and may disrupt participation at rugby clubs also. 
The successive waves of the ISM provide the opportunity to test whether the age profile of adult rugby players has shown any sign of change among successive cohorts in recent years. The data span 2007 to 2017. Splitting this period into two, as shown in Figure 2.3, reveals no evidence of any change. The small amount of variation apparent in the chart is not statistically significant, supporting the proposition that the age profile remained essentially stationary during this recent 2007 to 2017 period.

Figures 2.2 and 2.3 are derived from surveys undertaken in the Republic of Ireland. The SAPAS survey in Northern Ireland was conducted with a sample of adults only and can be compared with a consolidated profile derived for the same age group from the ISM. The resulting comparison is shown in Figure 2.4. Again, there is a close match between the two sets of data, despite the different survey methods and reference periods.

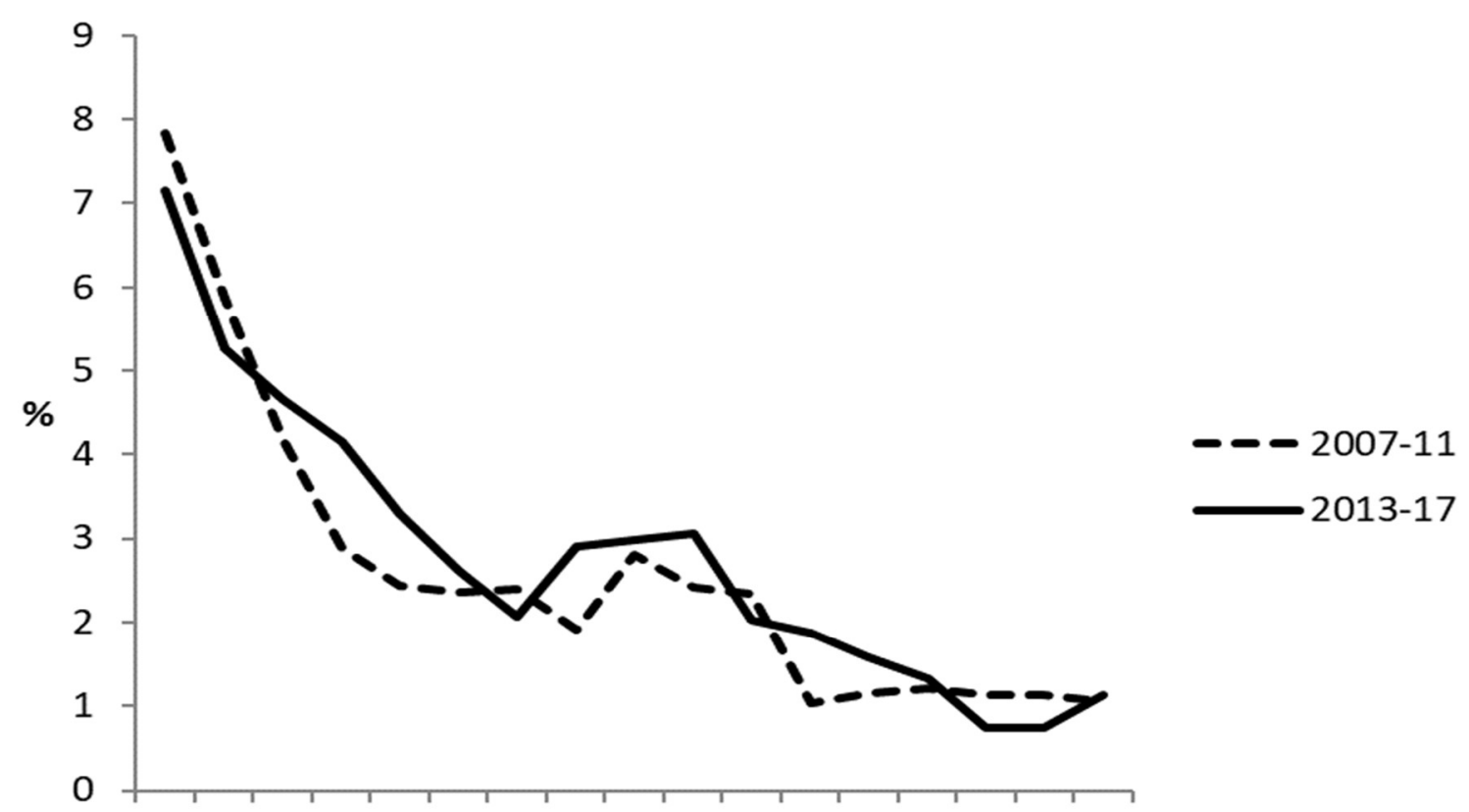

1718192021222324252627282930313233

Year of age

Source: ISM 


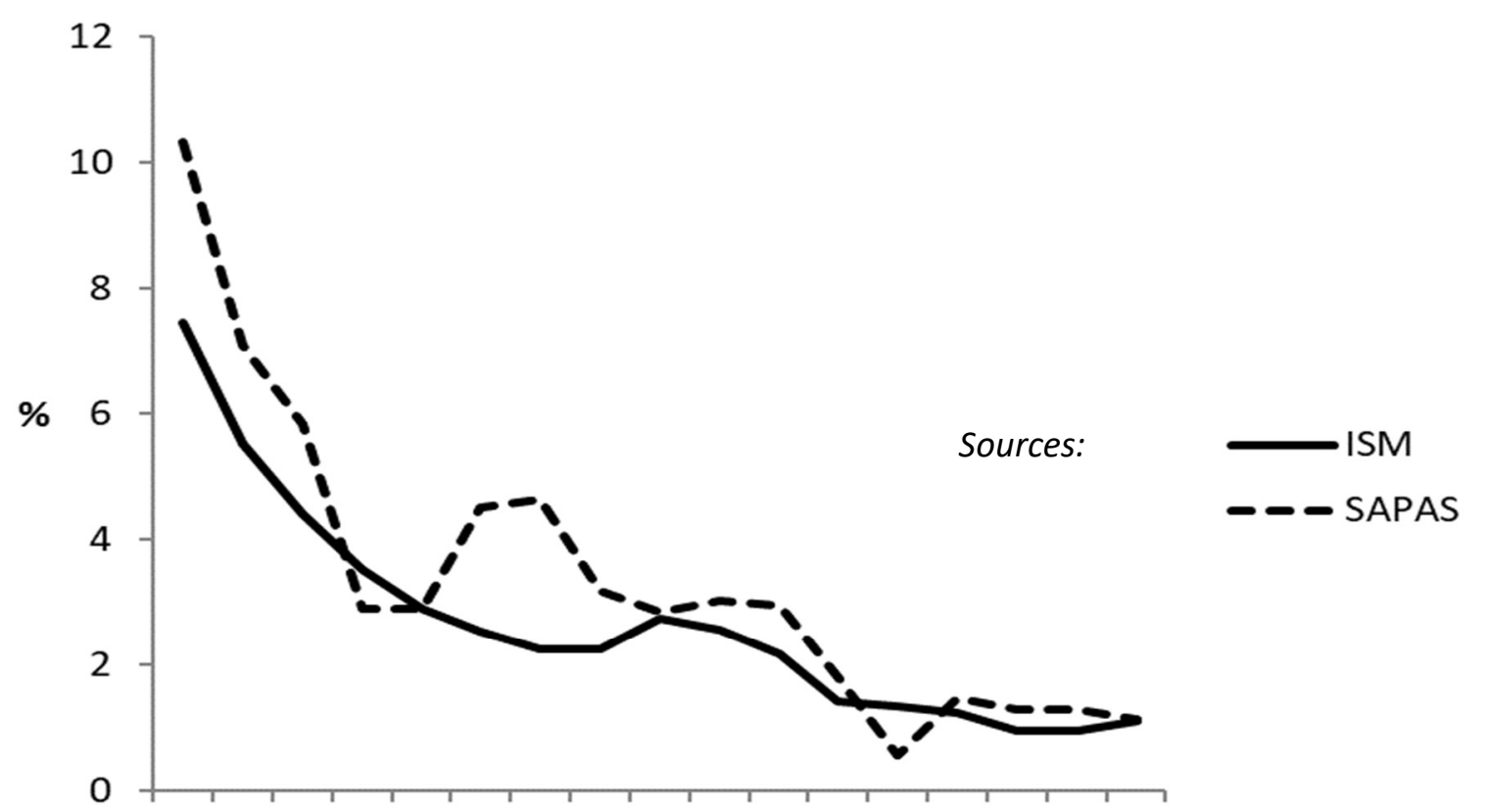

1718192021222324252627282930313233

\section{Year of age}

Note:

SAPAS represents Northern Ireland; ISM represents the Republic of Ireland.

One noticeable aspect of the more detailed age profiles for adults presented in Figures 2.2 and 2.3 is that participation rates are fairly flat through the early to mid-twenties. Once an individual has continued to play rugby after leaving school, they appear to stick with the sport until their late twenties and sometimes beyond. A much higher proportion of continued active participation among adults involves the full 15-a-side game (see Section 2.5).

Lastly, it is possible to use the ISM data to generate a useful comparison of post-school drop-out across the major field sports. This is helpful because it effectively acts as a test of one possible explanation for the precipitous decline in participation between ages 17 and 20 years. One possibility is that the physical nature of rugby makes it more difficult for individuals to make the transition from playing with peers of the same age to playing with adults who may be several years older and more physically developed. If this is an important factor, the post-school decline in participation ought to be more severe for rugby.

Figure 2.5 shows simultaneous age profiles of participation by young adults in rugby, soccer, Gaelic football and hurling. What is striking about this chart is that all four of the major field sports suffer from high levels of drop- 
out between the late teenage years and mid-twenties. In fact, the slope of the drop-out curve for rugby is less severe, especially in comparison to the two largest Gaelic games. This means that the participation rate in rugby by age 25 years approximates that for Gaelic football and hurling, having started out lower. The drop-out rate from soccer is less severe than for the two Gaelic games but still a little steeper than for rugby, although it starts from a much higher base. A significant proportion of soccer played in people's mid-twenties consists of five-a-side rather than 11-a-side, while a high proportion of participation in the other field sports, particularly the Gaelic games, continues to involve playing the full game. The smaller contribution of tag and touch rugby is examined in Section 2.5.

The key implication of Figure 2.5 is that it is not something unique to rugby that causes the large post-school fall in participation, such as its particularly physical nature. Other factors appear to underlie the phenomenon. Unfortunately, the lower sample size and data quality mean that it is not possible to do the same precise quantitative comparison of the major field sports for the transition from primary to second-level school. It is clear from the data, however, that there is also a substantial fall-off in involvement in Gaelic games, soccer and some non-team activities at this transition point. There is therefore no indication that this is a particular issue for rugby, or that rugby is being replaced with other sports. 
FIGURE 2.5 COMPARISON OF AGE PROFILES OF ADULT PLAYERS OF RUGBY, SOCCER, GAELIC FOOTBALL AND HURLING (ROI)

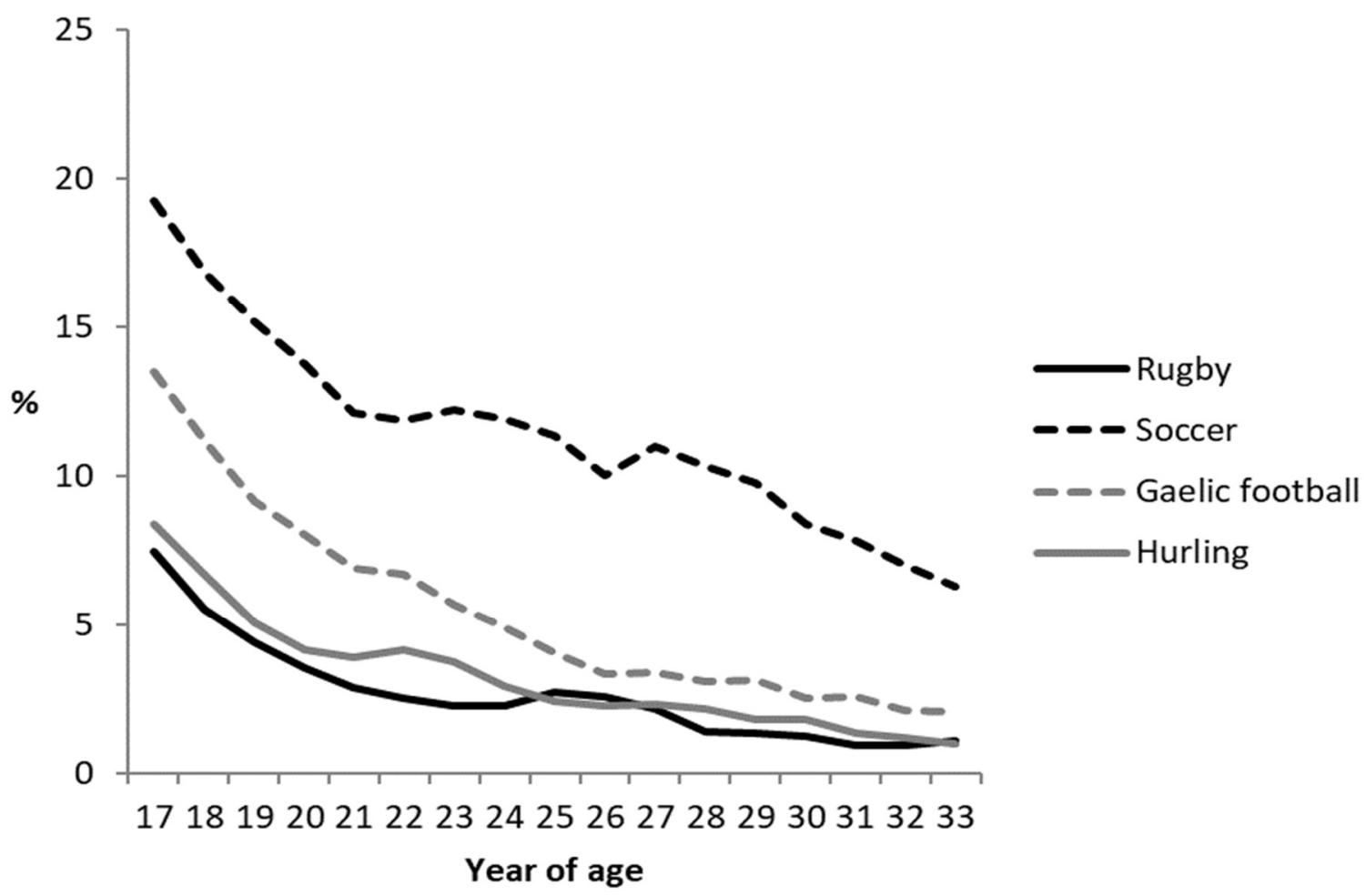

Source: ISM

From the perspective of policies to increase participation, the message of this subsection is plain. Participation in rugby among children in their final years at primary school is high, much higher than in previous generations. The CSPPA survey indicates that participation at this age involves a mixture of activity at rugby clubs and at school. Yet participation rates fall sharply at two specific and well-defined points of the life-course, when children move to second level and when they leave school. At both points, more than half of rugby players cease playing.

Throughout the second-level years and during people's twenties, the participation rate is very stable. One suggestion of this pattern is that overall participation in rugby may well be increased more by targeting drop-out than by trying to attract still more children to take up the sport. We return to this issue when examining the implications of the findings in Section 3. 


\subsection{HOW MALE IS RUGBY?}

Rugby is traditionally a male-dominated game, but women's rugby has enjoyed a substantially greater profile in recent years. This may in part be due to the increasing profile and performance level of Ireland's senior women's team and Ireland's hosting of the 2017 Women's Rugby World Cup. The available datasets can each be examined for the proportion of rugby players recorded who are female. The results are given in Figure 2.6 (darker shading indicates female).

\section{FIGURE 2.6 RUGBY PLAYERS BY GENDER}

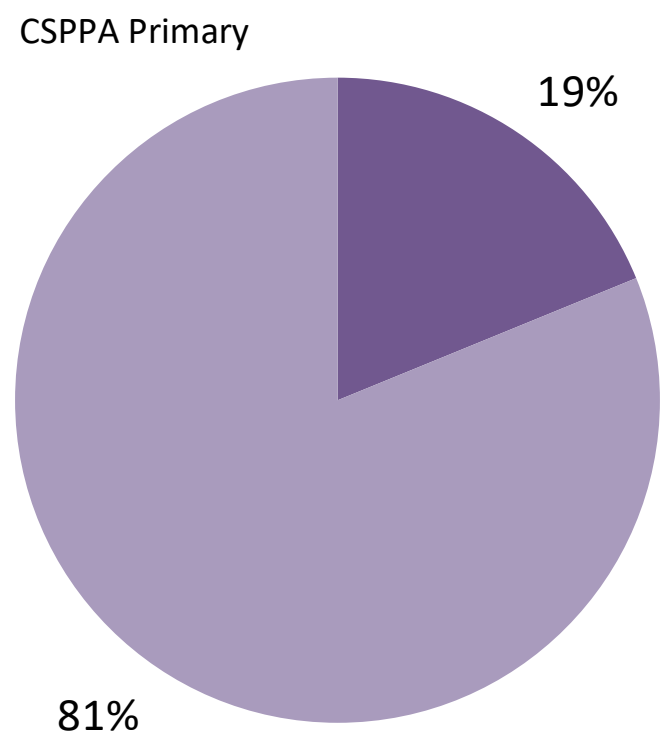

CSPPA Second level
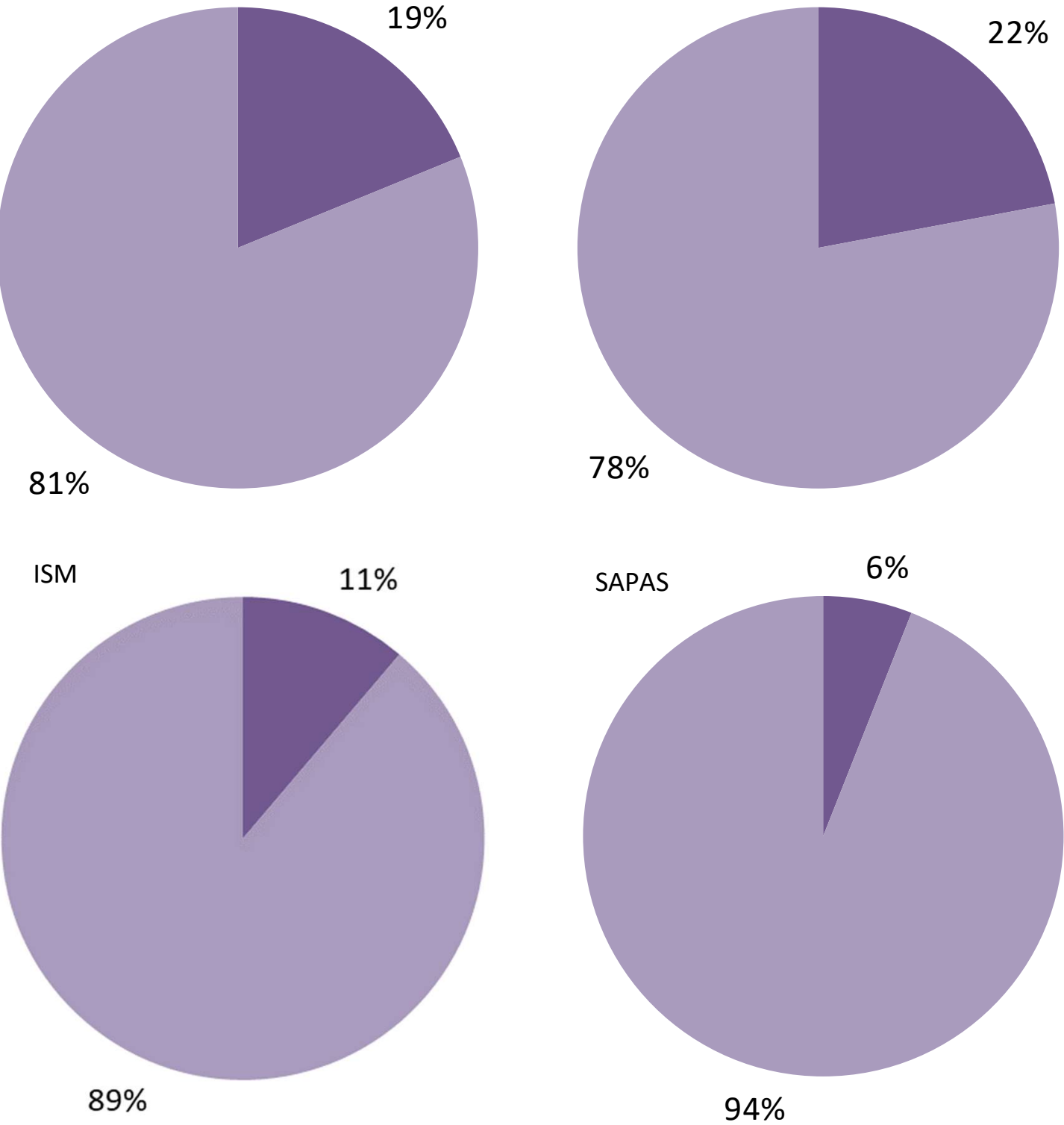
The margin of error on these percentage figures is relatively large, given that they are a proportion of an already relatively small proportion of survey respondents that participate in rugby. Nevertheless, the general pattern is clear and highly statistically significant. Children's rugby is a less male-dominated game than adult rugby. To some extent this is probably a cohort effect, such that when the current cohort of children reaches adulthood the proportion of adult rugby players who are women will increase. The substantial rise in the popularity of mini-rugby has clearly attracted more girls to play the game, but it is unclear at this time to what extent this change will ultimately translate into more women rugby players.

\subsection{HOW STRONG IS THE SOCIO-ECONOMIC INFLUENCE ON PLAYING RUGBY?}

There is undoubtedly a perception that rugby is a predominantly middleclass sport, often associated with prominent fee-paying schools. The available data allow a quantification of the association between the likelihood that an individual plays rugby and their socio-economic background.

The socio-economic characteristics of individuals are often highly correlated at an individual level with other potentially important background characteristics. Younger people, on average, have higher educational attainment. Those with higher educational attainment are also more likely to be in full-time employment and to earn a higher income, and so on. Individuals still in full-time education, meanwhile, are yet to achieve their ultimate level of educational attainment. In order to disentangle the respective influences of the many potentially important background variables, it is necessary to use multivariate statistical techniques that simultaneously control for them and that allow us to identify the impact of each of the important individual characteristics (education, economic status, earnings, etc.) on participation. In the present case, we use logistic regression to model the likelihood that an individual is an active participant in rugby, using the ISM data.

In order to provide an intuitive understanding of the output of the statistical models, we present 'odds ratios' for the likelihood of being an active participant in rugby. The odds ratios correspond to the relative odds that a member of a particular category plays rugby relative to a reference category, which is assigned the value 1.0. For instance, suppose the reference category is 'Group $A$ ' and we are interested in the impact on playing rugby of being in 'Group B' instead of Group A. An odds ratio of 2.0 
associated with being in Group B would imply that membership of Group $B$ doubles the odds of playing rugby relative to membership of Group A. Similarly, an odds ratio of 0.5 associated with being in 'Group C' would indicate that membership of Group $C$ halves the odds of playing rugby relative to Group A.

Figure 2.7 shows the odds ratios for active participation in rugby by categories of educational attainment, as estimated in the statistical models provided in Appendix C. The reference category is individuals with upper second-level qualifications only (i.e. Leaving Certificate or equivalent). The chart displays a strong effect, such that higher educational attainment is associated with substantially higher odds of playing rugby. The odds that an individual who goes to college or university plays rugby are approximately twice the odds for an individual who ceases education at Leaving Certificate. The three separate bars in each category correspond to three different statistical models that control for different sets of background characteristics. The dark bars relate to statistical models that control for gender and age only. The mid-shade bars show the effect when we control in the statistical model for the full set of available background variables in the dataset except income (marital status, children in the household, residential location, region, employment status, car ownership and parental involvement in sport; see Appendix C). The lightest bars are calculated from a model that additionally controls for weekly household income. 


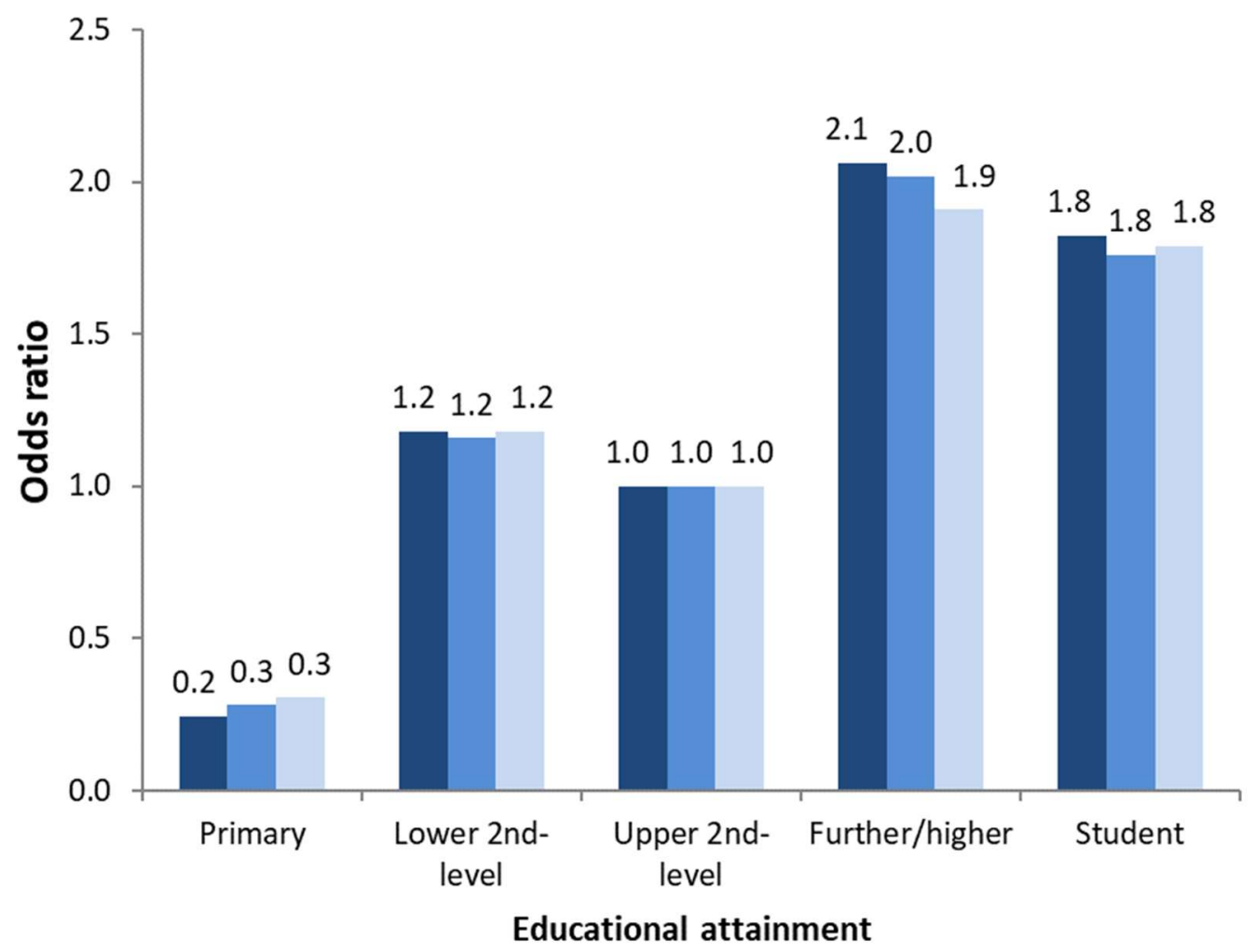

age controls $\quad$ Full controls Income controls

Source: ISM

These results reveal that the impact of educational attainment on whether an individual plays rugby is strong and consistent. Current students and those with post-secondary or third-level qualifications are far more likely to play rugby than individuals with lower levels of educational attainment.

The sample size of the SAPAS survey does not permit us to run the equivalent analysis for Northern Ireland, as it is not feasible to control simultaneously for such a broad range of background characteristics. However, the raw correlation between educational attainment and playing rugby in the SAPAS data is, in fact, even stronger than that depicted in Figure 2.7. It is reasonable to surmise, therefore, that the relationship between educational attainment and playing rugby in Northern Ireland is likely to be similarly strong to that in the Republic of Ireland.

Over and above this relationship, we examined the effect of household income on the likelihood of playing rugby. The results are provided in Figure 2.8 and can be easily summarised. We split the income distribution 
into three evenly sized groups. A fourth 'missing' group is also shown, because a high proportion of respondents are not willing to provide income information. Results for this group are similar. As the chart shows, those in the bottom third of the income distribution are approximately half as likely to play rugby as those in the two higher groups. One important aspect of this pattern is that playing rugby is not strongly concentrated among the best-off in society, because the likelihood of participation in the middle-income group is closer to that of the higher-income group than to that of the lower-income group. The implication is that those in the bottom third of incomes are particularly unlikely to play, even after controlling simultaneously for all available background characteristics. ${ }^{4}$

\section{FIGURE 2.8 ODDS RATIOS FOR ADULTS PLAYING RUGBY BY INCOME (ROI)}

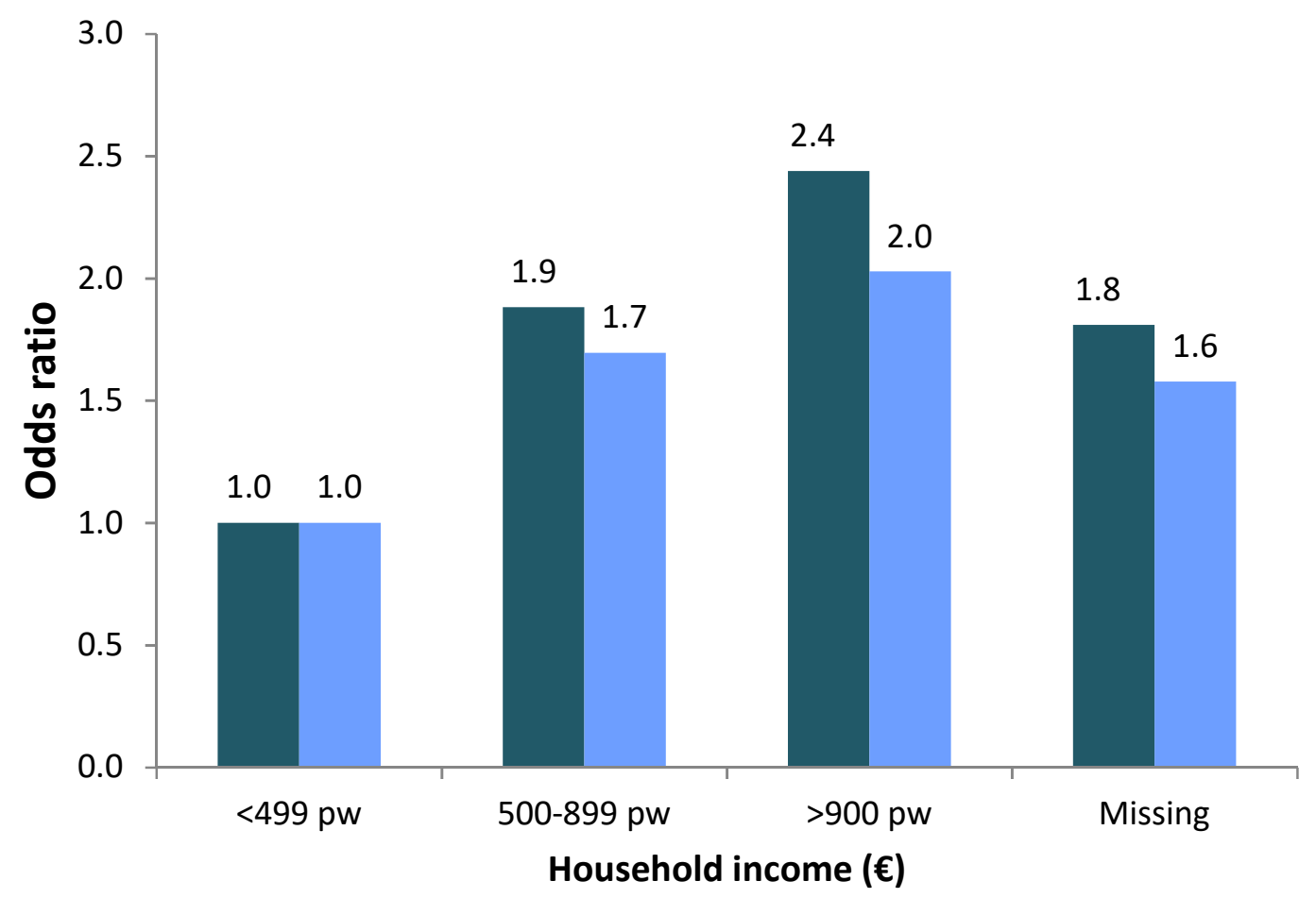

Age controls Full controls

Source: ISM.

This last point about controlling for other characteristics is an important one. Although it is the case that individuals with higher educational attainment also tend to have higher incomes, the statistical models imply

$4 \quad$ Some caution is required here, as rugby players tend to be young and a proportion are likely still to live with their parents. The income information captured by the ISM is household income, not personal income. If young adults from higher- and middle-income parental homes tend to leave home at different ages, this could add some noise to the results. Nevertheless, the size of the difference in Figure 2.8 suggests that the primary effect is lower participation among the lowest income group. 
that both these factors have substantial and mostly independent effects on the likelihood of playing rugby. The overall conclusion that must be drawn is that an individual's socio-economic circumstances are very strongly associated with the likelihood of playing rugby. This is a key conclusion for the present report and is addressed further in Section 3 (although the regional variation highlighted in the following subsection should be noted).

In addition to the above indicators of socio-economic status, the statistical models test whether any of a broad range of background characteristics has an effect on whether an individual plays rugby. The models do not record many significant relationships. Married people play rugby less than single people (controlling for age). Employment status generally has little influence, except for a modest but statistically significant effect associated with self-employment: the self-employed are more likely to play. Car ownership has a positive relationship with playing. The small proportion of people who had an inactive father but a mother who was active in sport while they were a child are less likely to play rugby. Whether an individual has children and their residential location (city, town, village, isolated location) have no effect. ${ }^{5}$

\subsection{DOES THE PATTERN OF PARTICIPATION VARY BY REGION?}

The active participation rate is broken down by region in Figure 2.9. It is not possible to produce comparison figures for Northern Ireland. Given sample-size limitations, the three Ulster counties outside Northern Ireland ${ }^{6}$ are grouped with the counties of Connacht. Munster is recorded as having the highest active participation rate. The difference relative to other regions is short of statistical significance. That is, there is some evidence here that participation in rugby may be higher in Munster than in the other regions, but we cannot be sure of this.

However, this overall comparison of active participation by region masks what is perhaps a stronger and more telling difference in the regional pattern - one that is statistically significant. The socio-economic influences highlighted in the previous subsection are not consistent by region. Figure 2.10 displays a comparison of odds ratios for playing rugby by educational

5 Some caution is warranted in interpreting the effects of background characteristics described in this paragraph. None of them is particularly strong and a large number of such tests are contained in the tables, so there is a danger that any one result may be a 'false positive', especially if the effect was not hypothesised beforehand. Thus, greater evidential weight can be placed on the findings for educational attainment and income.

6 Cavan, Donegal and Monaghan. 
attainment for Leinster and Munster. Equivalent estimates for Connacht/Ulster are not included in this chart, because the available sample size makes them too noisy to be meaningful.

\section{FIGURE 2.9 PARTICIPATION RATE BY REGION (ROI)}

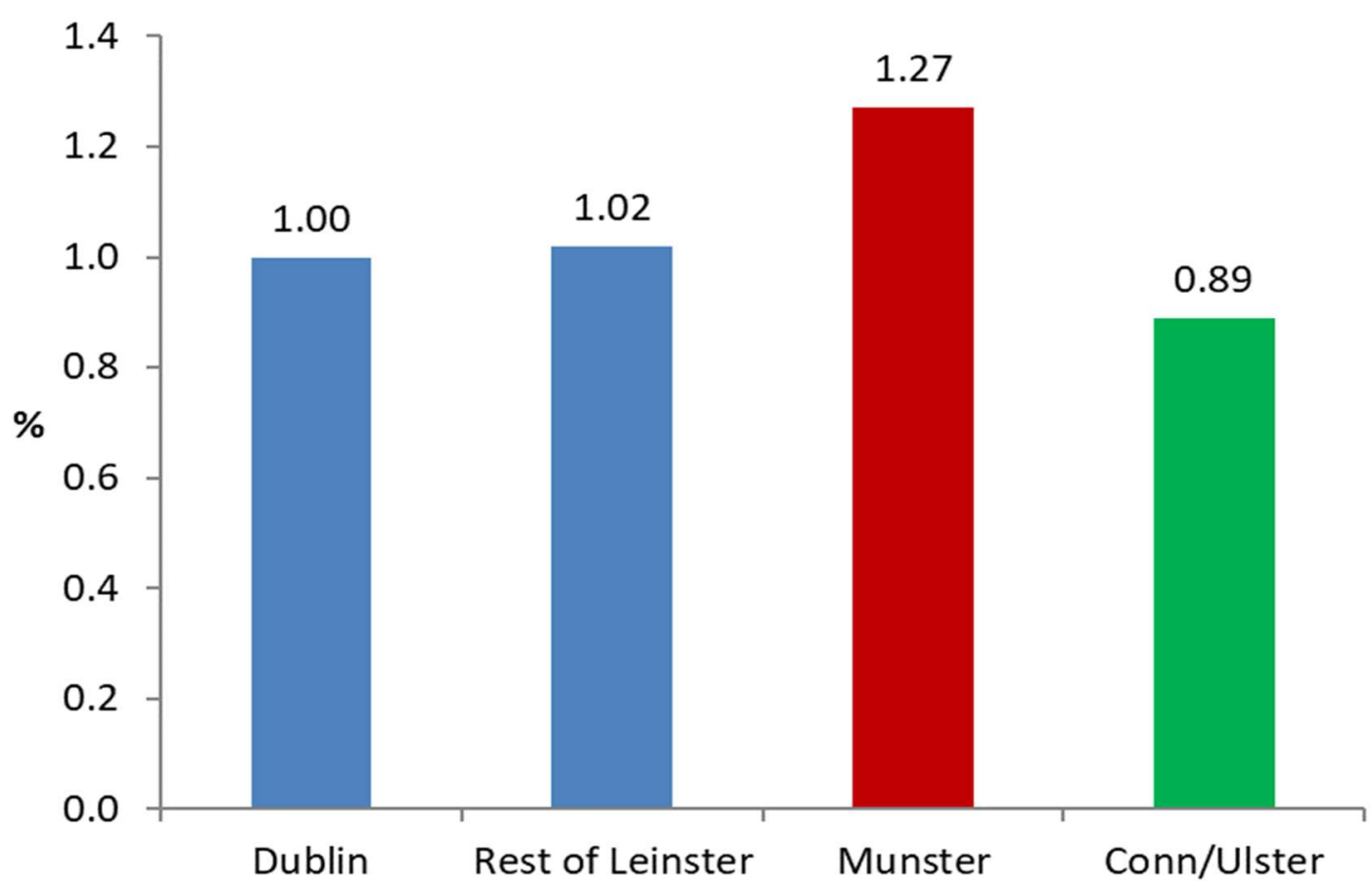

Source: ISM.

The picture is striking. The gradient in the likelihood of playing rugby by educational attainment is weaker in Munster than it is in Leinster. Two aspects of this analysis are worth noting. First, the obvious implication is that rugby in Munster has a broader social base, perhaps contributing to its higher rate of active participation overall (Figure 2.9). Second, the scale of the socio-economic effects highlighted in the previous section underestimates the phenomenon in Leinster, where they are particularly strong. In Leinster, the odds that an individual with a third-level qualification plays rugby are well over twice as high as the odds that an individual with only upper second-level qualifications plays. As noted above, sample-size limitations in Connacht/Ulster do not permit an equivalent precise analysis, although we note that the available data do not indicate the steep socio-economic gradient displayed for Leinster in Figure 2.10.

Educational attainment is only one measure of socio-economic status, so, given the strong findings depicted in Figure 2.10, it is important to look at 
another indicator. Figure 2.11 conducts a similar but somewhat different exercise by categories of income. In this case, the comparison is made between Munster and the rest of the country. By this measure, the relationship between socio-economic status and playing rugby is strong in Munster also, although the difference is largely confined to lower participation among the lowest third of the income distribution, with both middle and high earners being more likely to participate.

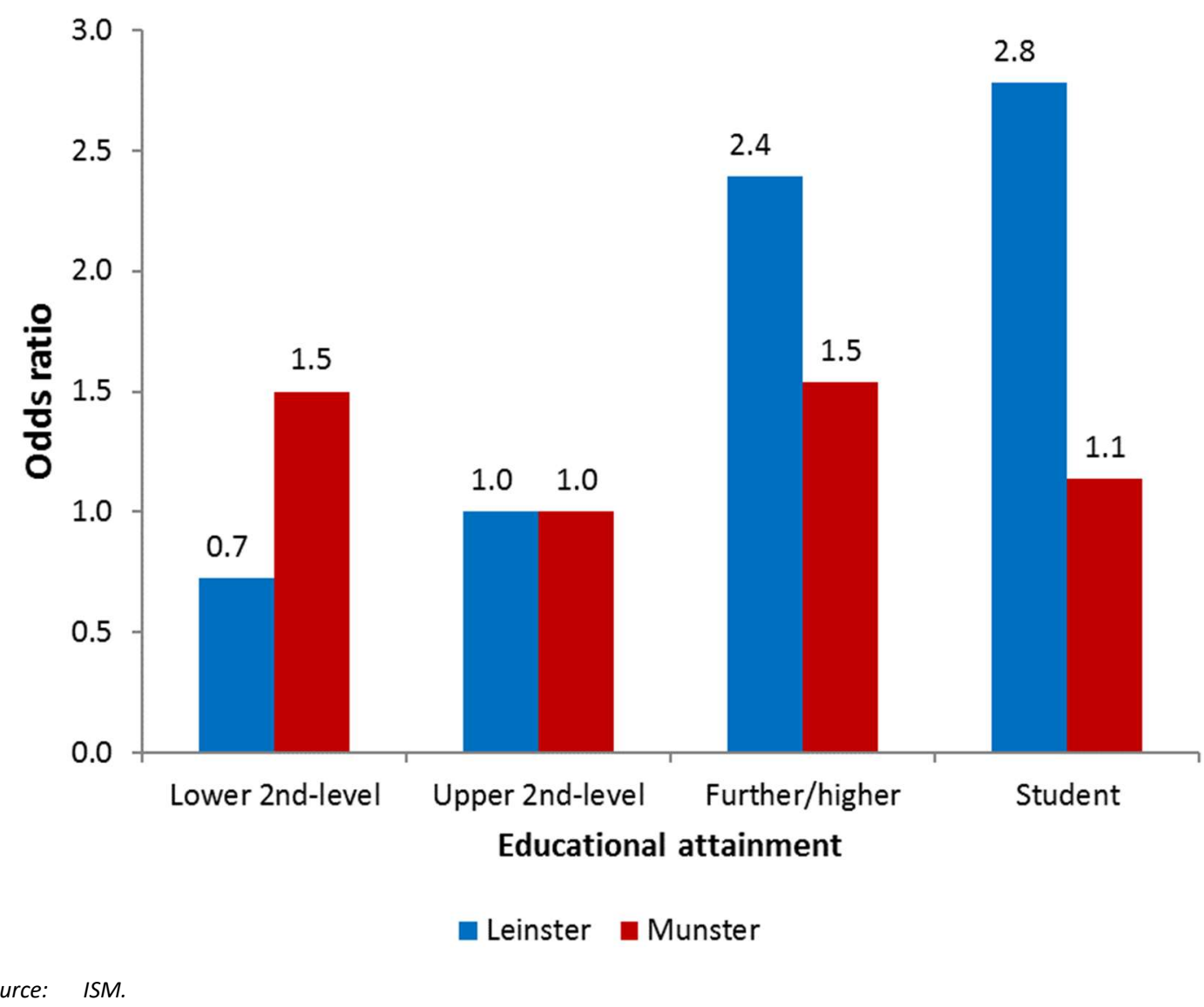

The differences apparent in Figure 2.11 are not as striking as those in Figure 2.10, but they do add an important dimension to the regional story. There remains a substantial socio-economic element to rugby in Munster. While those with middle incomes are more likely to play rugby than is the case in the rest of the country, participation remains substantially lower among the group with lowest incomes in Munster.

To summarise, there is evidence that rugby in Munster enjoys additional popularity, perhaps in part because of its appeal among a broader socio- 
economic spectrum of the population. The relationship with educational attainment implies that part of the explanation may lie in a weaker link (in comparison to Leinster) between active participation in rugby and attendance at specific and predominantly middle-class schools and colleges. It is possible too that rugby clubs in Munster play a stronger role within communities, although we have no independent evidence of this. Precise estimates for Connacht/Ulster are difficult to produce with current data, but the indication is that the very strong relationship between playing rugby and educational attainment may well be a phenomenon that is largely confined to Leinster.

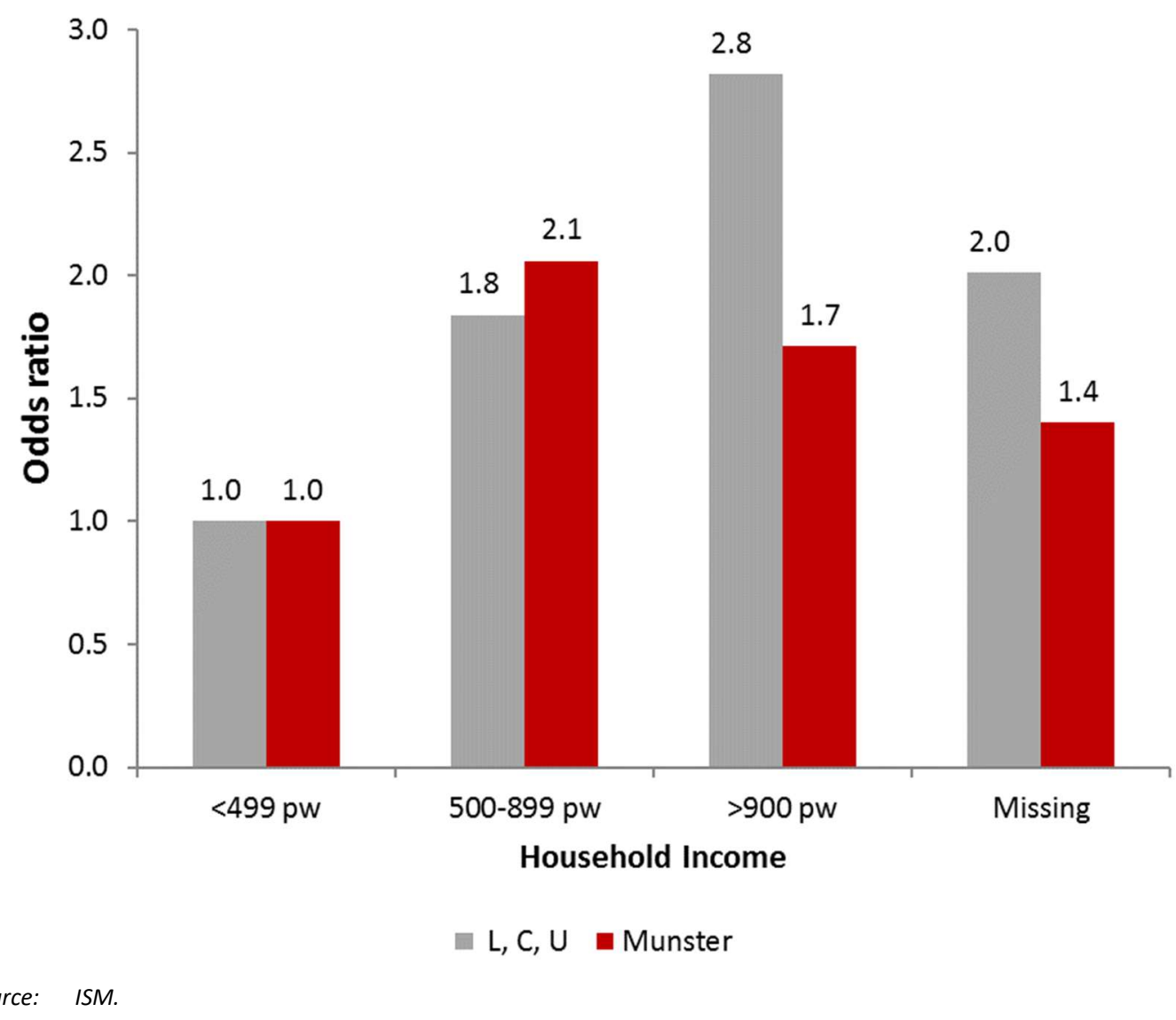

\subsection{FITT ANALYSIS}

FITT stands for 'frequency, intensity, time and type' and it is a standard approach to the analysis of data on active participation in sport. The aim is to understand what participation involves more precisely in order to assess its contribution to overall physical activity. This is important in the context of the large volume of research that now links physical activity to good 
health and wellbeing outcomes (see Appendix A). ${ }^{7}$ This subsection applies the technique to active participants in rugby.

Firstly, however, it is important to establish the relevance of the research question. Many people might think that participation in team sports is primarily about competition and camaderie. It might be assumed that while health and fitness benefits accrue to individuals who play, this is not their primary motivation. One module of the ISM survey, undertaken with over 7,000 respondents in 2007, was designed in part to test this assumption. The survey asked those who participated regularly in sport about their motivations for participation. Various factors were listed and participants had to rate them.

The results for team sports are shown in Figure 2.12. They reveal that physical wellbeing (on the survey the full statement was 'improving physical health and fitness') is deemed to be a 'very important' motivation by a greater proportion of participants than any other motivation listed. It is followed by the physical sensation, improving performance and mental wellbeing, all of which are more likely to be rated as very important than either competing with others or social benefits.

There is also potential for some negative health outcomes associated with the sport. A number of issues have been raised in recent times: the risk of serious injuries (especially head injuries); the potential for young people playing competitively to 'overtrain' or to take damaging levels of nutritional supplements; and the possibility that participation in team sports like rugby can be linked to excessive alcohol consumption. These issues are beyond the scope of the present report, as we have no data available in relation to them. 


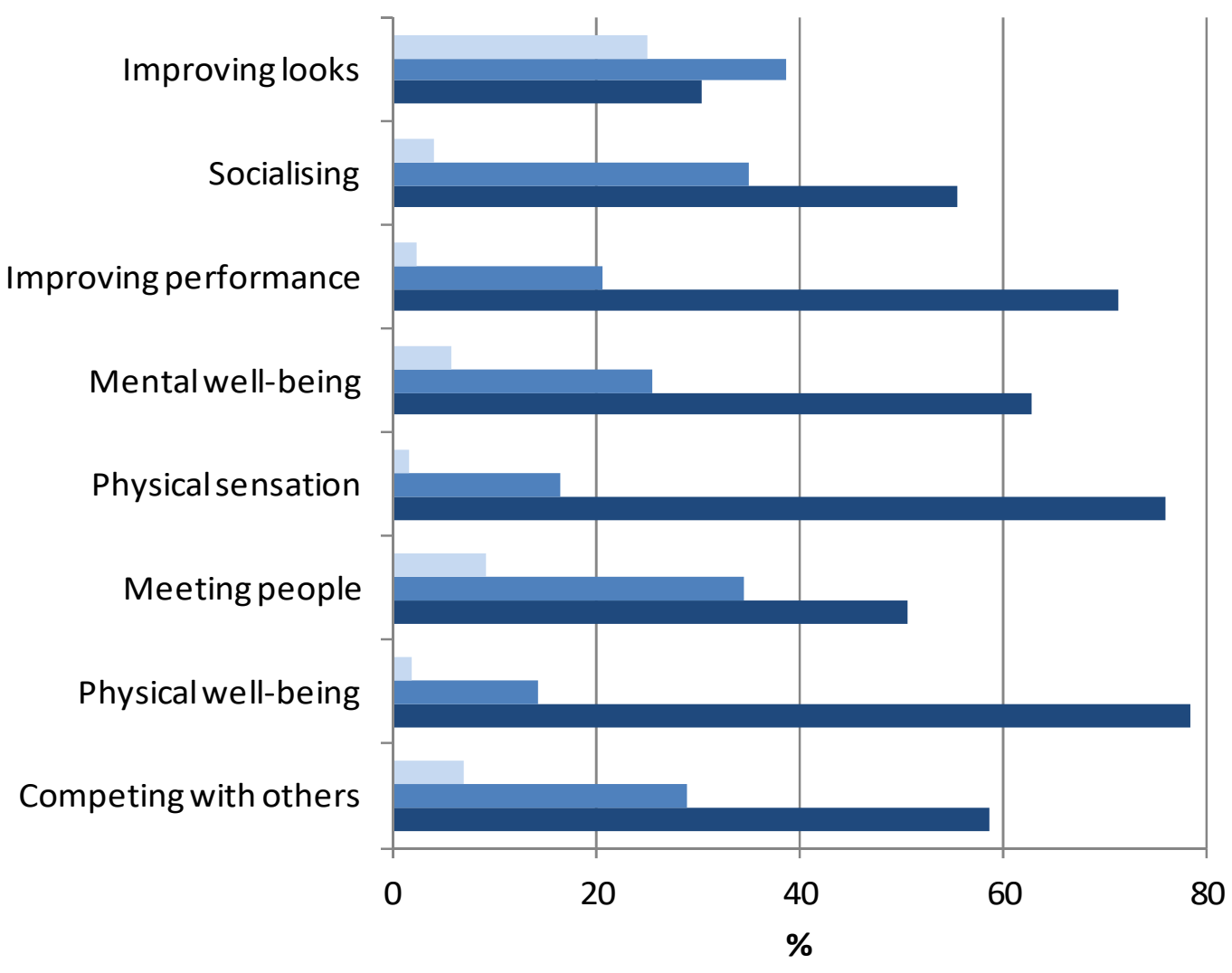

Not Somewhat $\square$ Very

Source: ISM.

It is unfortunately not possible to produce such a fine-grained analysis specifically for those who play rugby, as opposed to team sports (which overwhelmingly consist here of soccer, Gaelic games and rugby), because the sample of rugby players who undertook the module containing this survey question is too small. Nevertheless, there is nothing in the responses to suggest that rugby is any different from the other team sports in this regard - the pattern for rugby is not statistically distinguishable from that for the other team sports.

From this analysis we can conclude that a large majority of rugby players see physical health and fitness as a primary motivation for their active participation in the sport. In the broader context of research findings on participation in sport, this is not especially surprising. Previous ISM findings (see Appendix B) reveal that more recent generations of young Irish adults overwhelmingly view physical activity as something that is highly beneficial to their health and something that, in most cases, they wish to do more of. 
This previous research shows that the difficulty for them is to fit such activities around their busy lives.

Figure 2.13 charts the frequency of participation (in training or informal practice, as well as in matches) of rugby players recorded in the ISM data. The results reveal that most Irish adults who had played rugby during the previous 7 days had done so more than once. Overall, the average rugby player plays twice a week, though there is a good bit of variation around this figure.

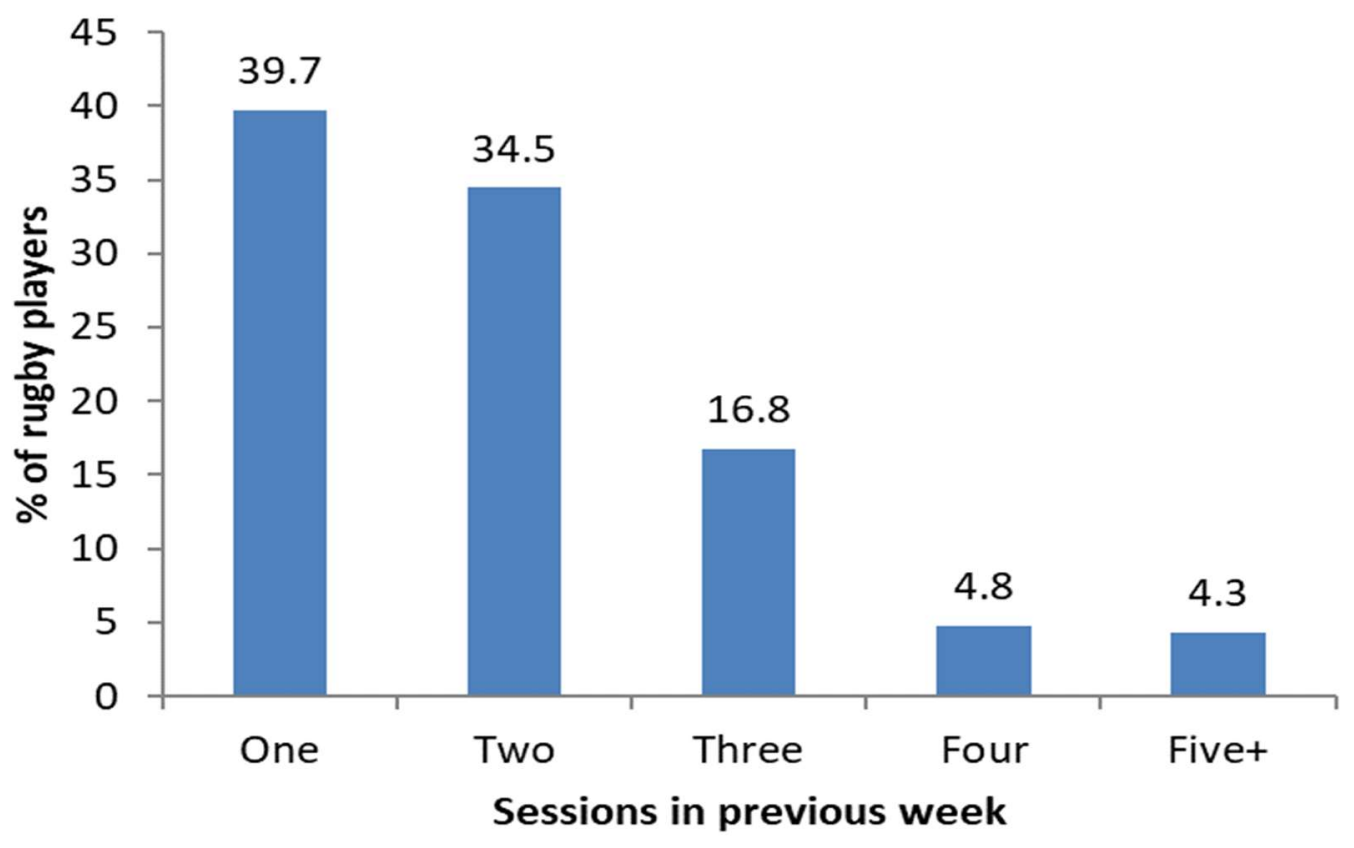

Source: ISM.

A standard international method for measuring the intensity of participation in sport is to ask survey respondents to gauge the extent to which a session causes them to be out of breath and to sweat. One might anticipate, given that rugby is generally considered to be a high-intensity sport, that most regular rugby players participate with sufficient intensity to meet this criterion, although some training sessions that focus on skills or tactics might not be so physically demanding. In fact, Figure 2.14 shows that 95 per cent of sessions leave the participant out of breath or sweating, suggesting that their participation in rugby makes a substantial contribution to their levels of physical activity and, hence, health and fitness. 


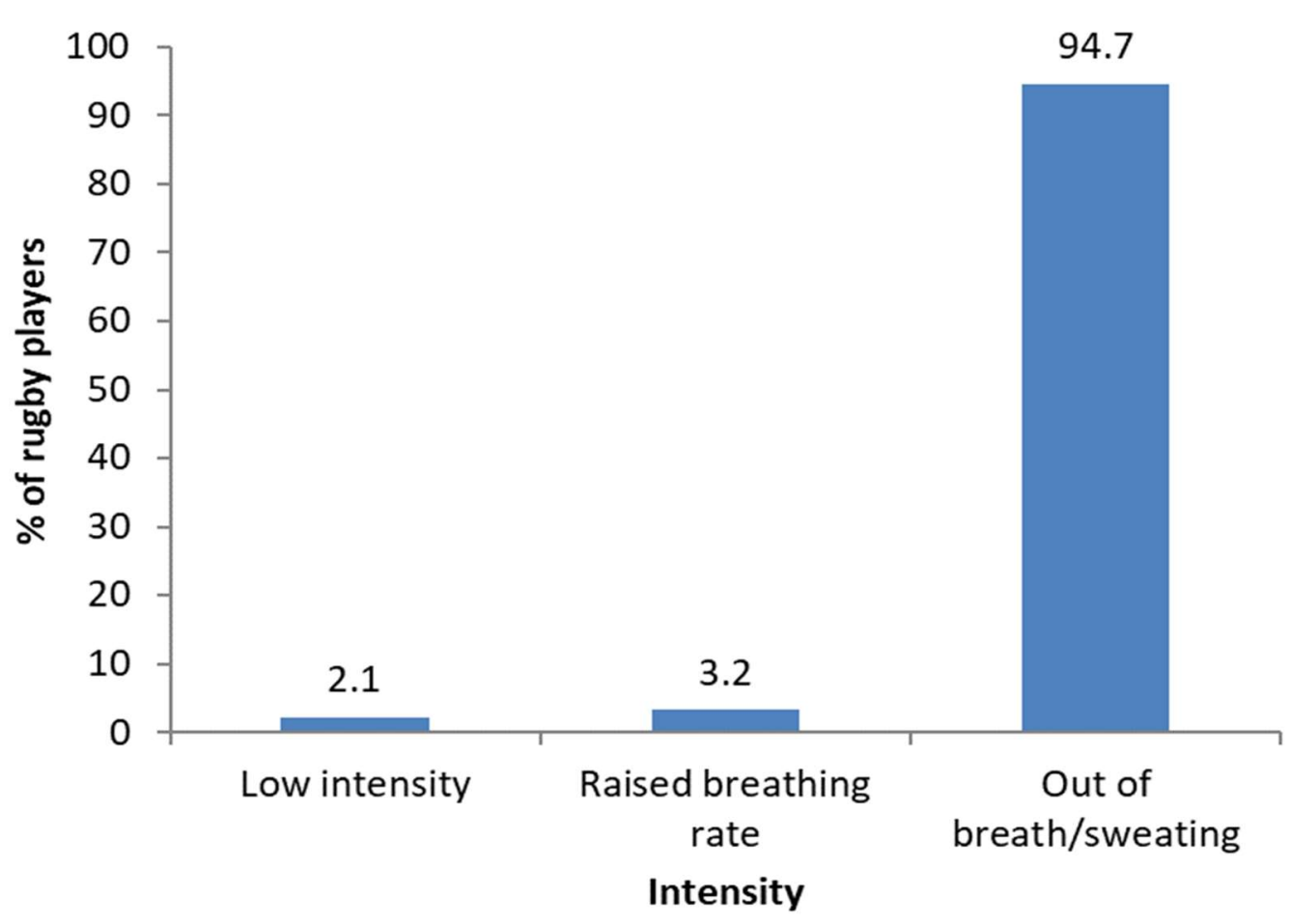

Source: ISM.

That contribution is made more substantial if the session of active participation lasts longer. Since a rugby match is played over more than 80 minutes, with additional activity likely to be involved in the warm-up before the game and the cool-down afterwards, many sessions might be expected to be relatively long, but training sessions or more casual participation might not involve such long durations. Figure 2.15 presents results with respect to the duration of sessions as recorded in the ISM. More than two-thirds of sessions last more than one hour. Among the 35 per cent that last less than one hour, a large majority last for between 30 and 60 minutes.

The remaining standard indication of the nature of active participation sessions relates to the context in which participation takes place. This can be important from a policy perspective, as where the proportion of participation that takes place in an organised setting is higher, the implication is that the schools, clubs and governing bodies that run the sport enjoy greater levels of, and opportunities for, contact with those that regularly play the game. From the perspective of communication and interaction with players, including with respect to player welfare, the participation context therefore matters. 


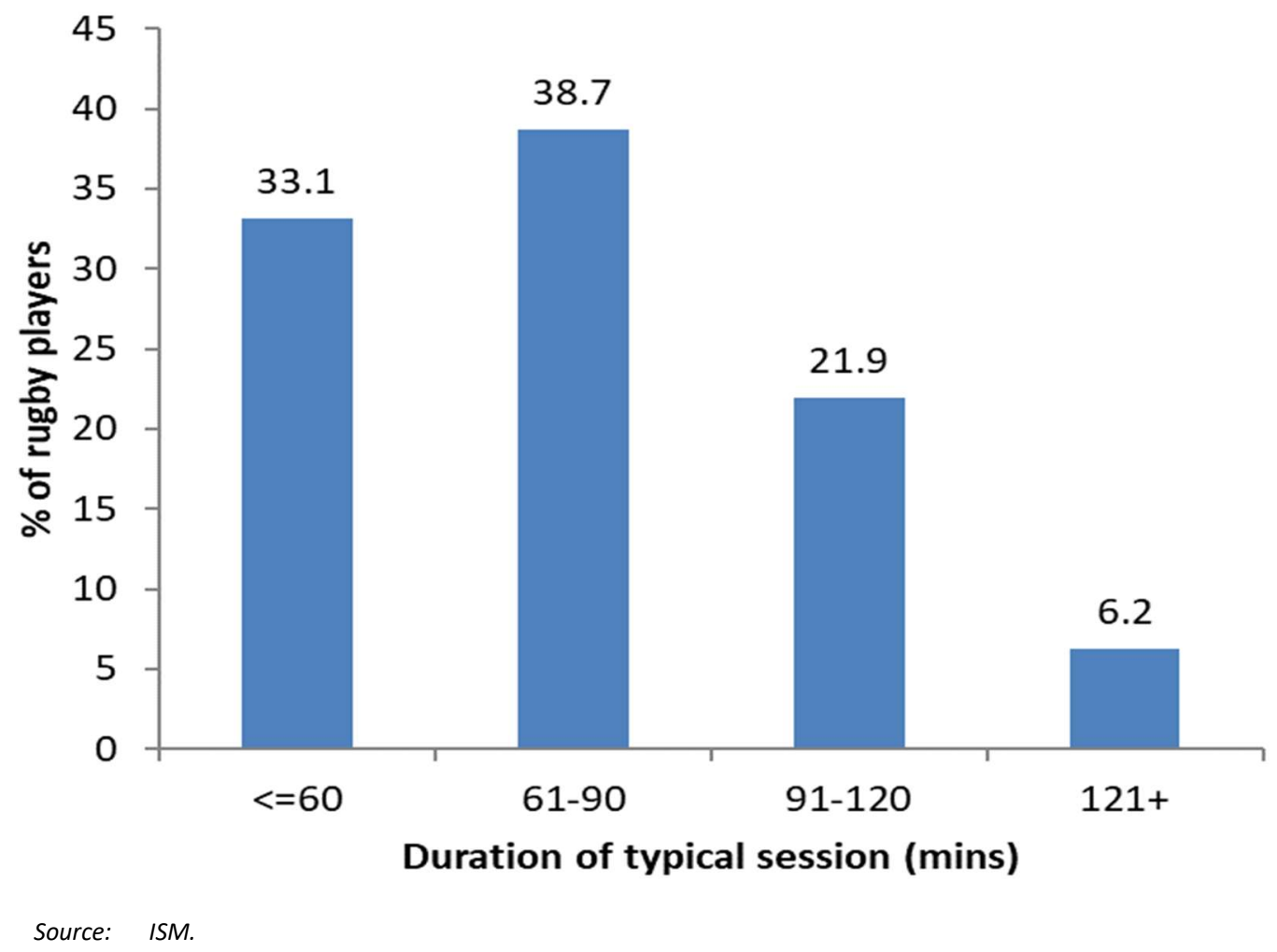

Figure 2.16 shows the breakdown of contexts in which active participation in rugby took place, as recorded in the ISM survey. The left panel reveals that 86 per cent of sessions took place in an organised context, either a match or a training session. The remainder consisted of participation in a more casual setting. Compared with many other activities, this is a relatively high level of participation in an organised setting. In at least some other sports, the likelihood of casual as opposed to organised active participation is linked to age. For instance, the proportion of soccer that is played casually increases through people's twenties, as organised participation in a club tends to give way to more casual participation, such as playing five-a-side with workplace colleagues.

To test whether there is any similar pattern in rugby, the right panel of Figure 2.16 shows the proportion of participation that is organised, as opposed to casual, by age group. Although there is a slight rise in casual (i.e. self-organised) participation in the twenties, there is not a consistent tendency for participation to become more casual with age. The most likely explanation for this pattern is that, like the full 15-a-side game, tag or touch rugby generally takes place in an organised setting. 


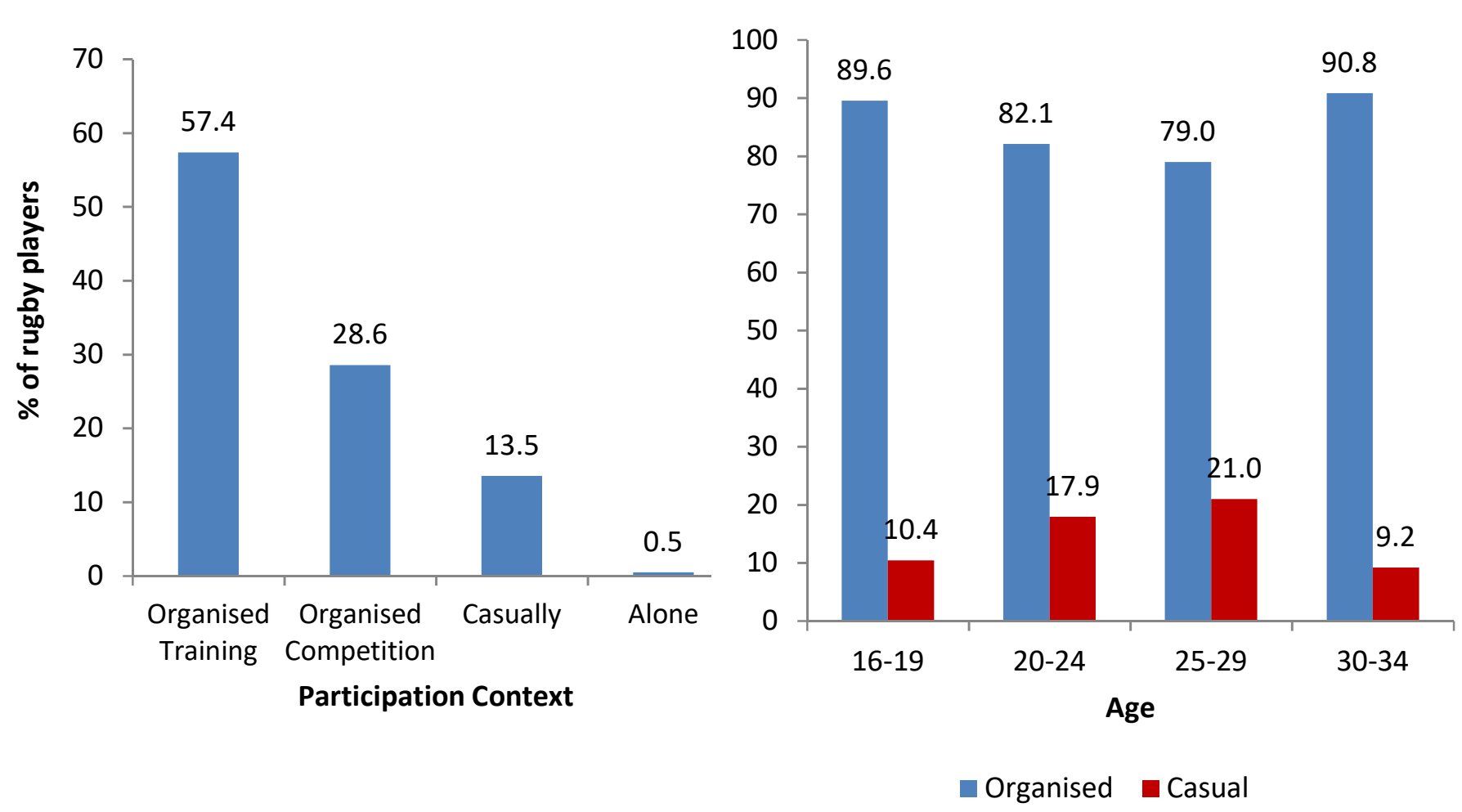

Source: ISM.

In all of the above analysis, no distinction is drawn between playing full contact 15 -a-side rugby and playing touch or tag rugby. Figure 2.17 provides a breakdown of the proportion of rugby played that is touch or tag, by age category. Less than one in ten sessions are accounted for by touch or tag rugby among those aged under 25 years, but the proportion climbs somewhat thereafter, to around 20 per cent of rugby played. This figure reflects the growth in organised tag rugby since the early 2000 s. ${ }^{8}$ Yet the degree to which 15-a-side rugby and touch or tag rugby are linked is unclear. In the ISM data, very few rugby players reported being involved in both forms of the game within a single week.

With the present data, we have no way to test whether those who play touch or tag rugby have been players of the full 15-a-side game, either recently or in their past, or whether they have taken it up having never previously played rugby. One indication that there may be a good number in the latter category is that the gender balance in touch and tag rugby is different. In many instances it is organised as a mixed sport, and more than a quarter of the adults playing touch or tag rugby are female. Lastly, it 
might be thought that a much greater proportion of touch and tag rugby would consist of casual participation rather than organised training or matches, but, as mentioned above, this turns out not to be the case. More than three-quarters of the touch or tag rugby sessions recorded in the ISM data took place in an organised setting, although the majority were not linked to a rugby club.

FIGURE 2.17 PROPORTION OF ACTIVE PARTICIPATION IN RUGBY ACCOUNTED FOR BY 'TOUCH' OR 'TAG' RUGBY (ROI)

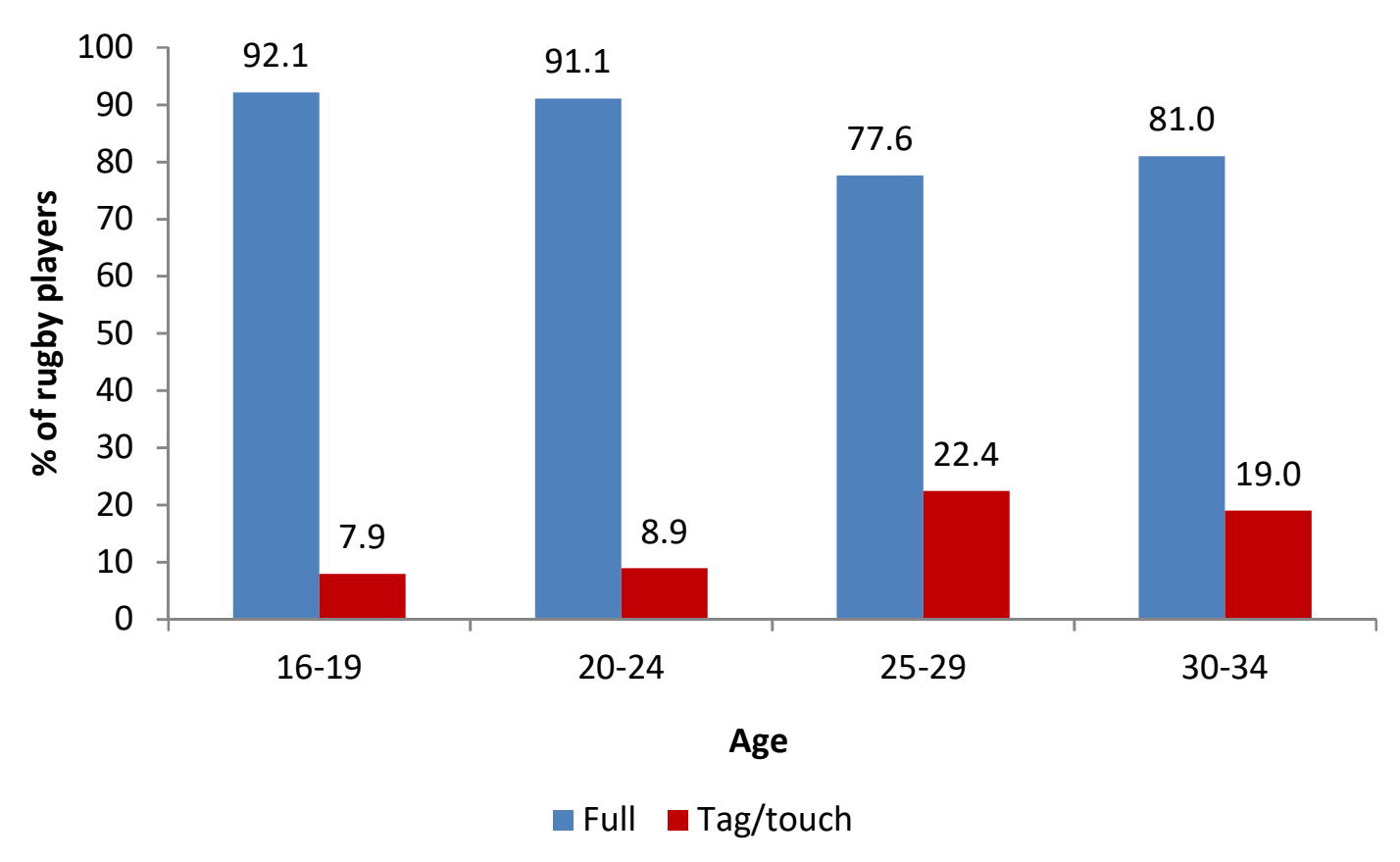

Source: ISM

\subsection{SOCIAL PARTICIPATION}

Social participation in sport is usually analysed in three categories: volunteering, membership of clubs and attendance at sporting fixtures or events (i.e. being a spectator). The ISM collects data on each of these aspects of social participation. Unfortunately, the SAPAS survey in Northern Ireland did not collect information on social participation specific to rugby, so the analysis in this subsection is based on the ISM data collected in the Republic of Ireland only.

Figure 2.18 shows the participation rates in these three forms of social participation among the general population. It is worth noting that there are more regular rugby club members and spectators than there are players, underlining the importance of social participation to the sport. Overall, by combining the information on playing, volunteering, club membership and attendance, the 2007 to 2013 ISM data record that 3.3 
per cent of the Irish adult population had engaged in some form of regular active or social participation in rugby within the previous seven days. This is equivalent to around 120,000 people having a direct engagement with the sport.

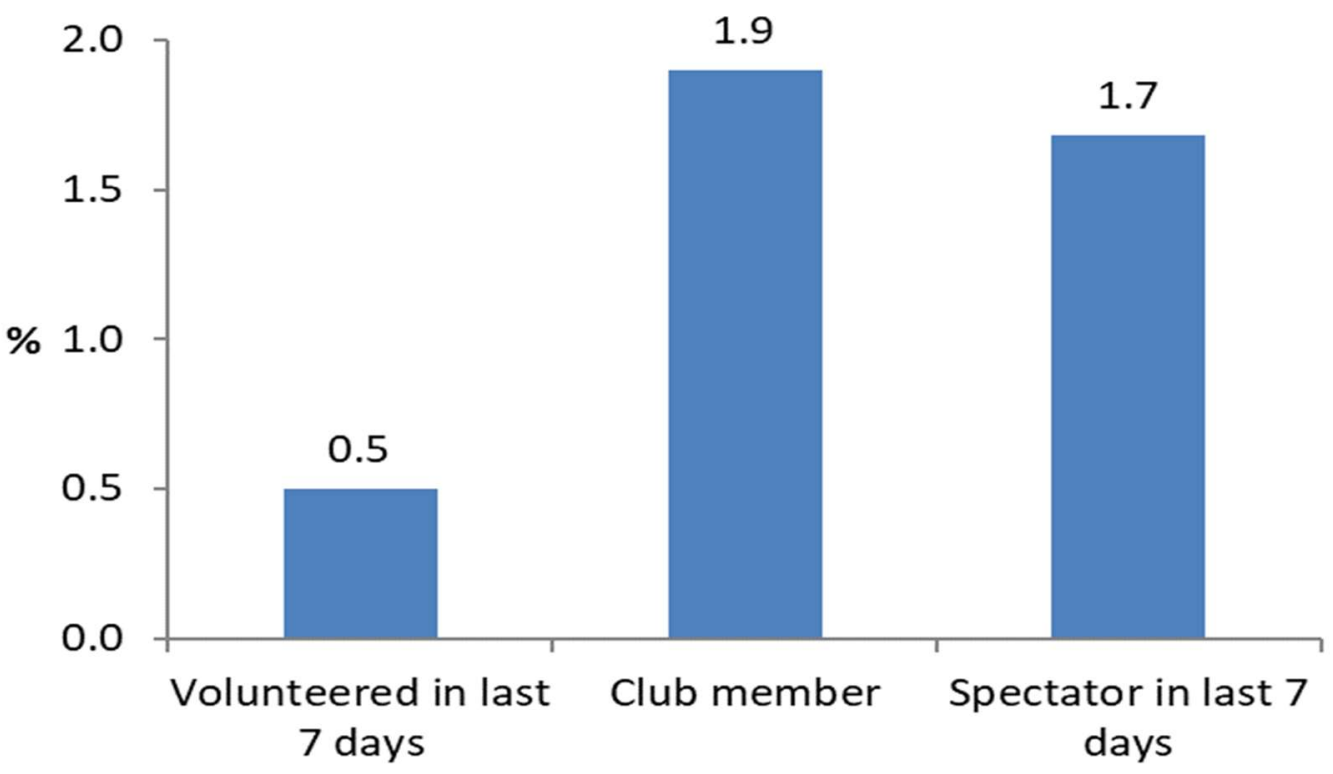

Source: ISM.

Unfortunately, the participation rate in volunteering for rugby within the general population is too low, at well under 1 per cent, for any meaningful additional analysis to be conducted on this group. The participation rates for club membership and attendance are sufficiently high, however, that it is possible to construct statistical models in a similar fashion to the models we generated for factors linked to playing rugby. For those interested in the statistical details, some of these models are reproduced in Appendix D.

Figure 2.19 breaks down the active and social participation rates by gender. This reveals that the gender imbalance in rugby is also strong for club membership, but weaker for attendance at fixtures and events. Women make up more than one-third of spectators at rugby matches. It is important to note that the survey makes no distinction here between watching the Irish men's and women's teams play an international at the Aviva stadium or Ashbourne and watching a son or daughter play a minirugby match - the percentage figures indicate the proportion who attended a rugby fixture or event of any kind. 


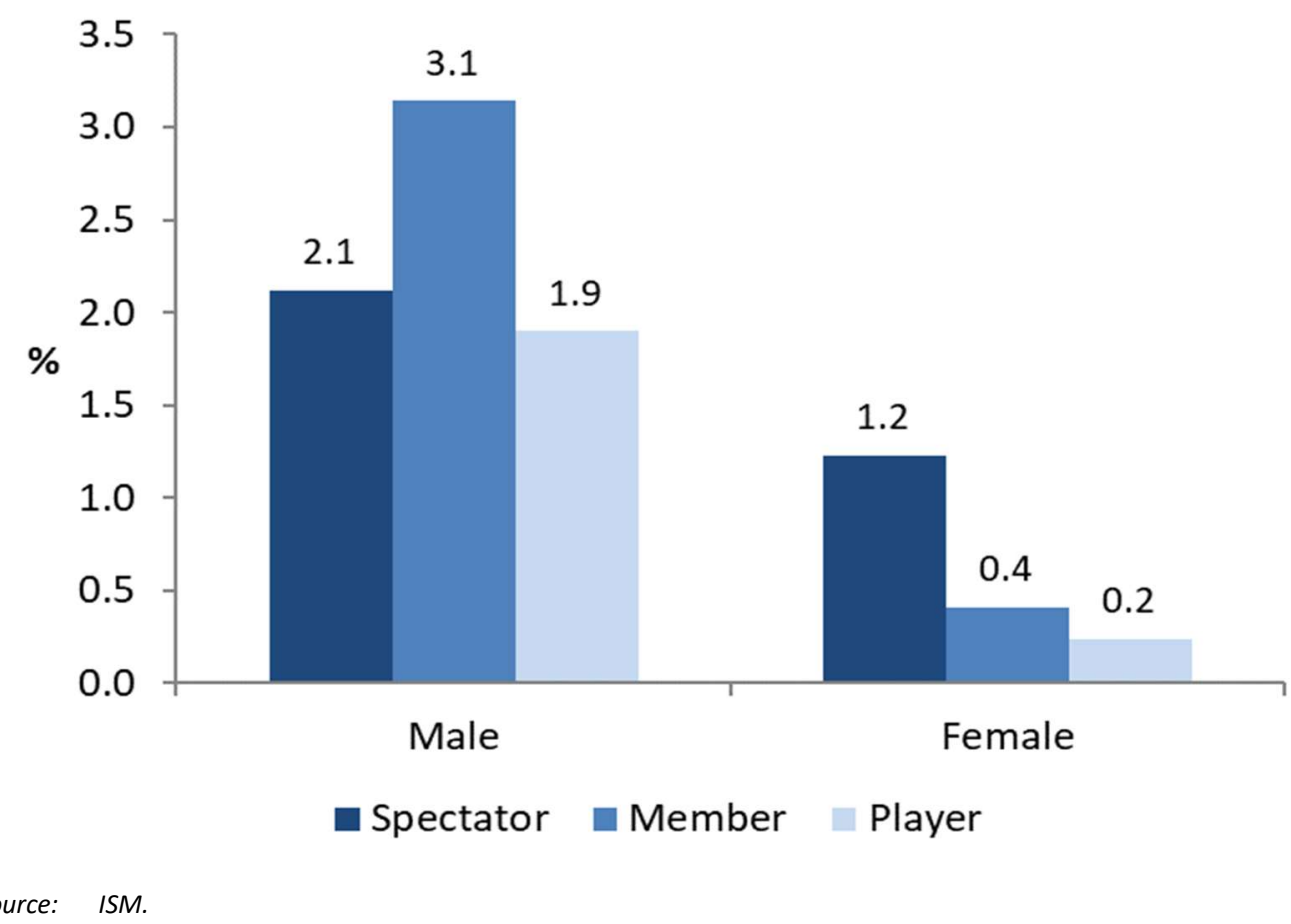

Figure 2.20 compares the age profile of spectators, club members and players across the adult life-course. Several aspects of this chart are worth dwelling on. With respect to club membership (black, dashed line), during young adulthood membership is all about playing. The two curves are very closely related and only begin to separate during people's twenties and, especially, beyond. Although we have no way to test this, the clear suggestion is that a substantial proportion of ex-players continue as nonplaying club members after they cease their playing careers. Once this transition has taken place, there is then very little drop-out in club membership as individuals progress through and past middle age.

Turning to attendance at fixtures and events, it is interesting initially to note that far more young adults are regular players than are regular spectators. In fact, of those who played rugby in the week prior to the survey, only around one quarter had gone to watch a match as well. Attendance has a more consistent age profile throughout adulthood than either playing the game or club membership, with one notable variation. There is a statistically significant increase in the likelihood of attendance between the mid-thirties and mid-fifties. 
The statistical models in Appendix D (Table D2), which control for the full range of available background characteristics, reveal that the main factor behind this age profile is parenthood. Attendance at rugby fixtures and events is significantly more likely among individuals who have children aged under 18 years, which doubtless reflects a combination of watching children play the game and taking them to matches of different sorts. It is also notable that during this period the number of regular attendees at rugby fixtures and events far exceeds the number of club members.

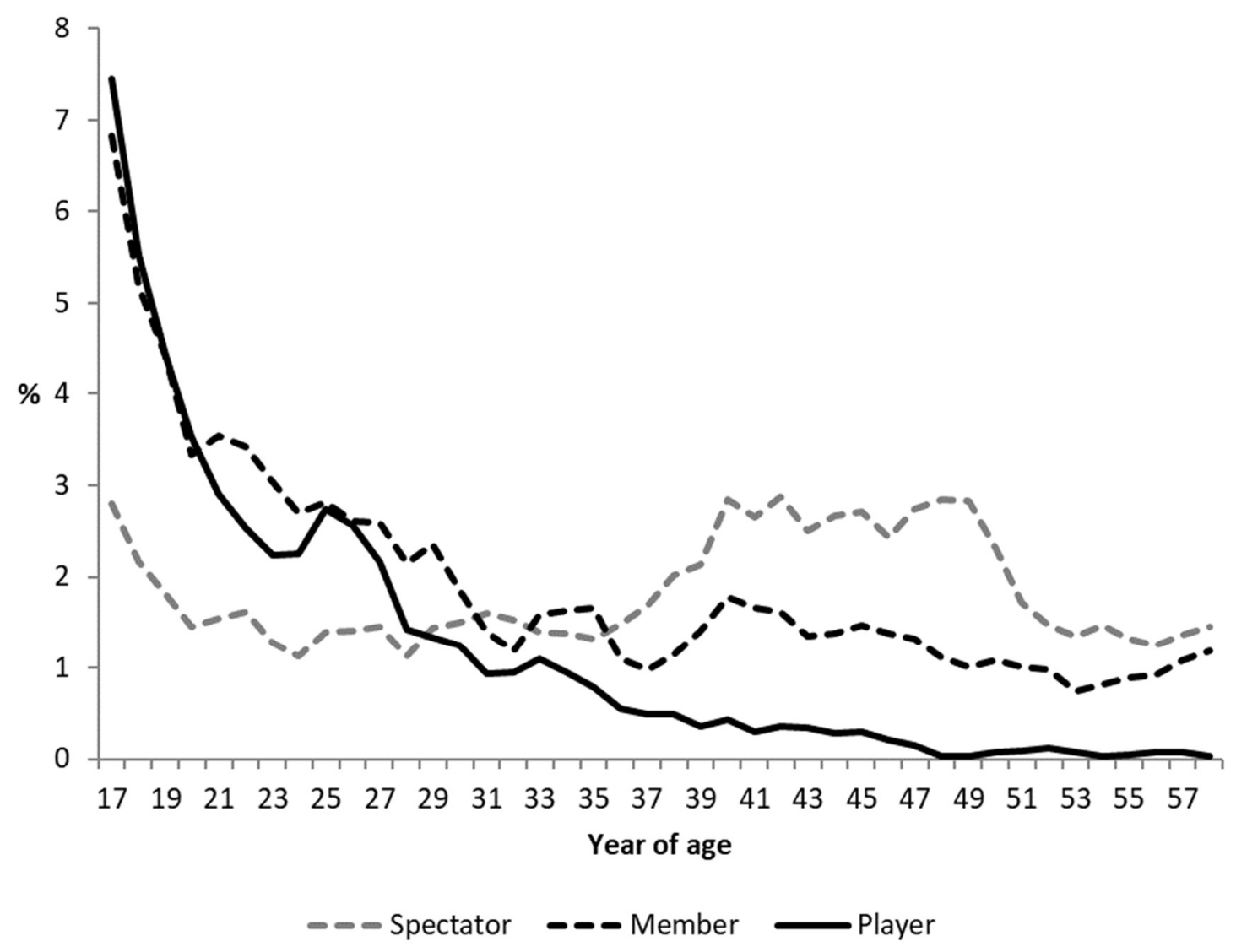

Source: ISM.

It is of interest also to ask whether the same socio-economic gradients apply to social participation in rugby as apply to active participation. Figure 2.21 presents odds ratios derived from equivalent statistical models for active participation, club membership and attendance. The socioeconomic gradients are at least as strong for social participation as for playing the game. 
As above, those with upper second-level qualifications are assigned the number 1.0 and the odds of participation of the other groups are expressed relative to this group. Hence, the models estimate that the odds that an individual with a third-level qualification is a member of a rugby club or watches a game are substantially higher than the odds that an individual with upper second-level qualifications does so, and very much higher than that an individual with lower second-level qualifications does so. These results are essentially unaffected by controlling for other background characteristics that might have an impact on club membership, including household income.

FIGURE 2.21 ODDS RATIOS FOR ACTIVE AND SOCIAL PARTICIPATION IN RUGBY BY EDUCATIONAL ATTAINMENT (ROI)

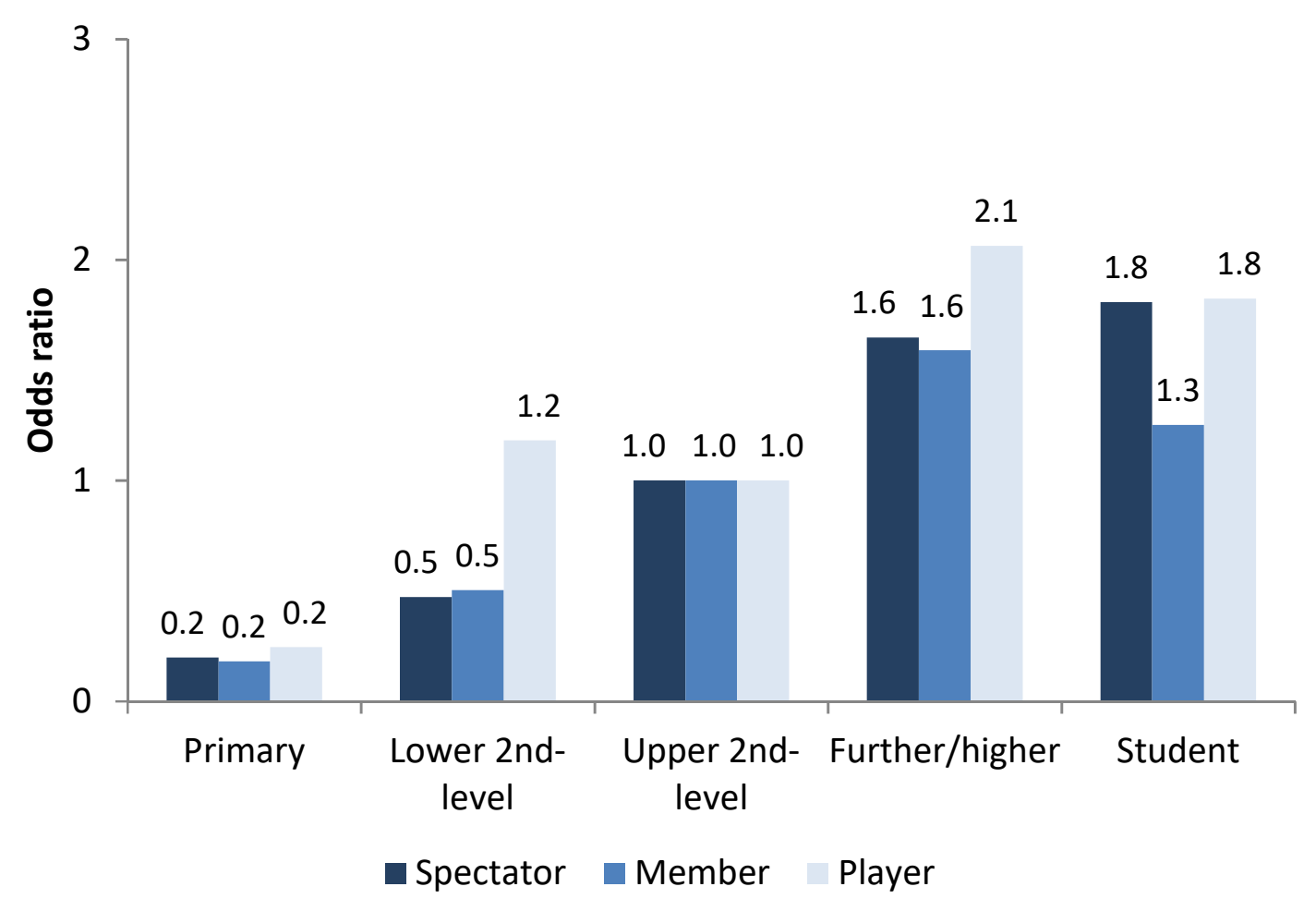

Source: ISM

Figure 2.22 repeats the analysis for household income, controlling for other background characteristics. The pattern for social participation is somewhat different to that for active participation, where the lowest income group are much less likely to participate than all other income groups. In contrast, social participation is much greater among the highest third in the income distribution than among other groups. This may reflect the expenditure involved in club membership or attendance at matches that charge entrance, although this hypothesis can only be regarded as a conjecture - we cannot test it with the available data. Note that while 
active participants are more likely to be young adults, who tend on average to have somewhat lower incomes than older adults, this cannot explain the effect, as age is controlled for in the statistical models that generate this pattern.

The statistical models in Appendix $D$ throw up a number of other interesting findings in relation to social participation, which is in general more strongly related to the range of background characteristics than is active participation.

Membership of rugby clubs is more closely associated with other socioeconomic indicators, including car ownership, self-employment, having children and living in a city. It is less likely among people who are separated or divorced, or who had two parents active in sport when they were children. Lastly, there is a regional effect too, over and above the impact of residential location. Club membership is more likely outside Dublin, especially in Munster, again confirming the region's higher participation in the sport overall.

FIGURE 2.22 ODDS RATIOS FOR ACTIVE AND SOCIAL PARTICIPATION IN RUGBY BY HOUSEHOLD INCOME (ROI)

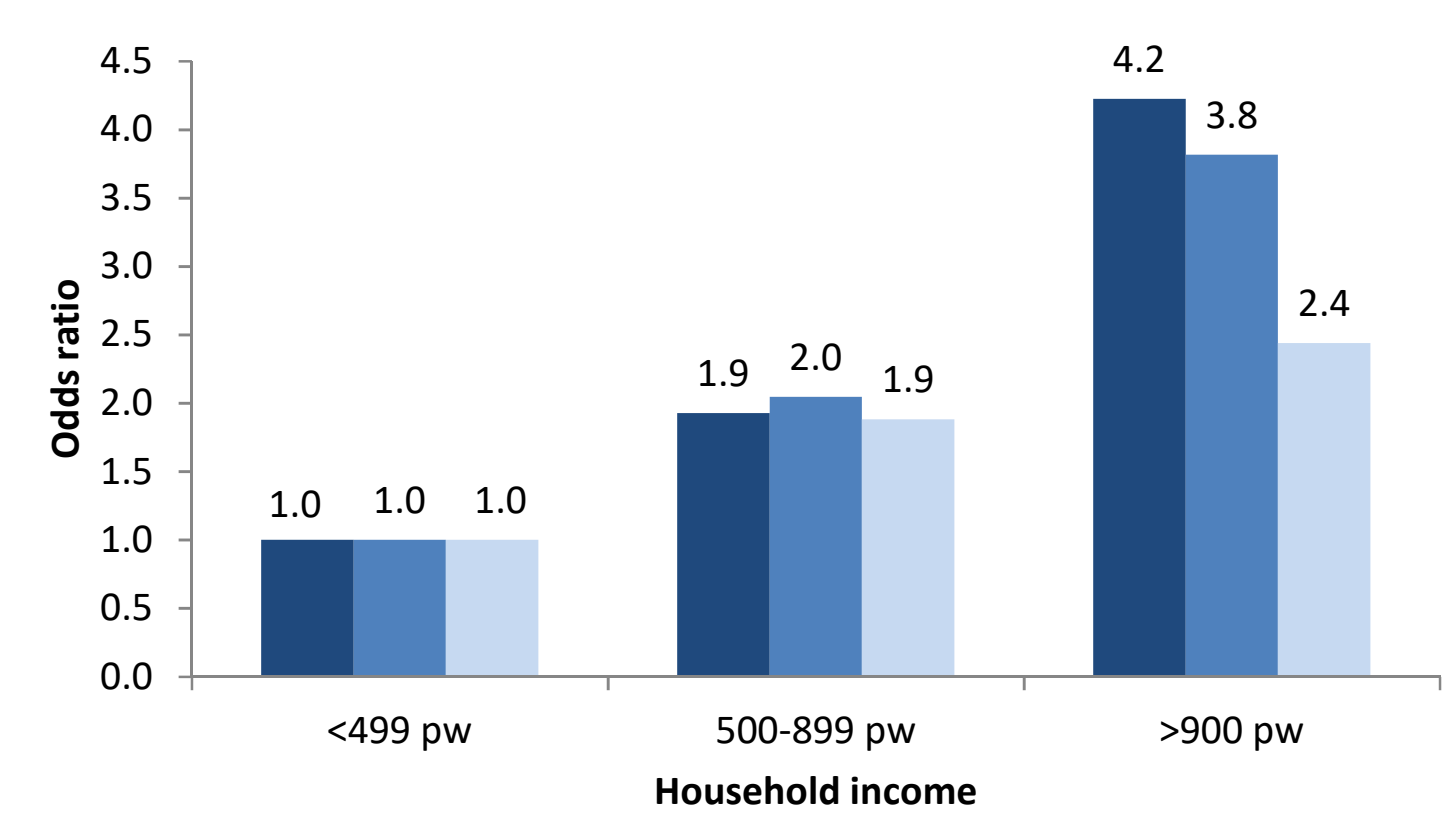

- Spectator Member Player

Source: $\quad$ ISM. 
Attendance at a rugby fixture or event is also significantly more likely among those living in cities. Over and above this, attendance follows a regional pattern: least likely in the Connacht/Ulster region of the Republic of Ireland and most likely in Munster and the parts of Leinster outside Dublin. Attendance is more likely among individuals who have children and those whose fathers (but not mothers) played sport when they were children.

Although some caution is warranted in interpreting all these results, given the number of different tests and danger of 'false positives', the findings across these patterns of social participation are suggestive of broader influences. They imply that families and children are important drivers of social participation, with the caveat that children of sporting mothers may have less involvement than children of sporting fathers. The results also confirm the popularity of rugby in Munster. 


\section{CHAPTER 3}

\section{Conclusions}

This chapter briefly recaps the main statistical findings before offering some policy implications of the results for discussion.

\subsection{STATISTICAL FINDINGS}

The multiple data sources accessed and analysed for this report contain a broad range of findings that have the potential to inform policy that aims to increase participation in rugby, either by increasing take-up of the sport or reducing drop-out.

The data suggest that active participation has risen in recent decades among both adults and children. Just over 1 per cent of the adult population played rugby during the previous seven days, with a much higher proportion of children playing the game regularly. However, only a small minority of children who play rugby continue to play as adults. There are two crucial transition points at which individuals are likely to drop out from the game: on moving from primary to second-level school and on leaving second-level school. This pattern is apparent in Northern Ireland as well as in the Republic of Ireland. The rugby players that do continue their involvement after leaving school are unlikely to drop out; participation rates hold up well until the late twenties. This pattern of retention during adulthood compares well with the other major field sports. Furthermore, the substantial rate of drop-out at the two transition points is not unique to rugby but is common to the major field sports in Ireland.

Playing rugby has a strong relationship with several specific background characteristics. Four out of every five children who play rugby are male, while more than nine out of ten adults who play are male. Current students and individuals with higher educational attainment are substantially more likely to be active participants than those of lower educational attainment, while individuals in the lowest third of the income distribution are substantially less likely to play. These socio-economic gradients are not consistent across regions, however. Rugby in Munster is played by a broader cross-section of people than rugby in the rest of the country, although participants still tend to come disproportionately from higher income categories. This broader socio-economic base may well explain why participation in the sport is generally higher in Munster. 
Those who play team sports, including rugby, view health benefits as a primary motivation behind their active participation. The present generation of young adults understands that physical activity is good for health and many wish to be more active than they currently are. The data confirm that rugby players derive a substantial amount of vigorous physical activity from the sport. Most play or train more than once a week, for over an hour each time and with a level of intensity that is likely to confer considerable health benefits, provided they avoid serious injury. The greater part of rugby by far is played in an organised environment. Touch and tag rugby accounts for just over 10 per cent of rugby played, mostly among somewhat older adults (aged 25 years plus).

Social participation in rugby, measured by whether individuals are club members, volunteer or attend fixtures or events, makes a substantial contribution to the sport. More people are members of rugby clubs or watch rugby than play the game, primarily because being a club member or spectator is possible later in adulthood. Women are more represented in social participation, making up more than a third of spectators across all kinds of rugby matches. Parents are more likely to be spectators also. The socio-economic influences on social participation are, however, somewhat stronger for social participation than for active participation. Individuals with higher educational attainment and higher income are far more likely to be involved in rugby, in whatever capacity.

\subsection{POLICY IMPLICATIONS}

The primary challenge facing the IRFU and others who wish to see greater participation in rugby is not getting individuals to take up the sport, although of course more could be encouraged to do so. Rather, it is preventing those who do take up the sport at a young age from dropping out. The proportion of children playing the game regularly by their final year in primary school has increased greatly and is encouragingly high by historical standards. But the overwhelming majority of these young rugby players, male and female, drop out of the game as they progress through childhood and adolescence. The key statistical point is that if the active participation of even a small additional proportion of young players could be maintained into adulthood, it would have a substantial impact on the adult participation rate.

Although the participation rate among young children is substantial, there remains a need to focus on recruitment into mini-rugby. The demographic data presented in this report (Figures 1.1 and 1.2) show that the cohort of potential mini-rugby players, which is already increasing, is beginning to 
expand even faster. Because of substantial recent changes in the birth rate, as of 2019, the number of children aged between 7 and 11 years in the Republic of Ireland is more than 10 per cent greater than the number aged between 12 and 16 . Thus, rugby needs to be able to offer playing opportunities for greater numbers of young children if it is to maintain the improved participation rate in mini-rugby. The data show that a similar increase can be expected in Northern Ireland, although there has recently been a fall in numbers in the relevant age group.

The challenges and opportunities posed by demographic change do not stop there. The age profile of the population in the Republic of Ireland at present shows a large dip in young adulthood. The number of young adults has fallen very substantially over the past decade and a half. At present, the smallest cohort of Irish people aged under 50 years is 23 -year-olds. This explains why a sport that seems to be gaining popularity can simultaneously be struggling to maintain some adult teams. But over the coming decade this demographic trend will go into reverse. In the absence of dramatic emigration, the number of young adults is set to increase strongly for the next two decades. Rugby needs to prepare for the challenge of accommodating this increase in the population of young people, in the knowledge that the primary challenge will then be to prevent those who take up the game from dropping out as they progress into young adulthood. It might repay the IRFU to study regional demographic data and hence to get an idea of how this increase in the population is distributed across regions and counties.

Drop-out from rugby occurs overwhelmingly at two transition points in young people's lives: when they move from primary to second-level school and when they leave second-level school. It may be tempting for those within the sport to relate these transition points to associated changes in the nature of the sport: perhaps graduation to the 15-a-side game, greater competitiveness of rugby at second-level school, the more physical nature of adult rugby, and so on. While there may be some truth in these propositions, the evidence does not support the view that the primary factor behind these two distinct periods of drop-out is the nature of the sport. This is because these two transition points cause large-scale dropout in other team sports also. This is an important point, because bodies that govern sports tend to view participation in their sport as being driven mainly by participants' experiences of participation, such as the quality of facilities or coaching. The evidence does not support this view of drop-out as primarily a 'sports development' problem. Instead, it implies that the level of drop-out is mainly caused by the impact of the considerable changes in individuals' lives that accompany key transition points that are 
not directly related to the sport; drop-out occurs mainly when young people change school and leave school. The challenge for rugby, therefore, is to help young people to continue their involvement in the game across two periods of upheaval and increased busyness in their lives.

The present findings identify this challenge, but not its solution. Yet a number of possibilities present themselves. Dealing first with the transition from primary to second-level school, this a time when new routines (e.g. transport, childcare) are established in family life, free time is reduced by longer school days and increases in homework, while some existing social networks are lost and replaced by new ones. Amid such upheaval, proactive efforts to keep in touch with children who played rugby during their final year of primary school (and/or their parents), to encourage continued involvement and to communicate essential information about where and how to continue to participate, might make all the difference to keeping a young person in the game. A proactive strategy of maintaining contact with young players across the transition from primary to second-level school requires organisation and resources to be devoted to the task, but could produce a substantial return in terms of reduced drop-out from rugby.

A similar type of solution involving proactive contact might be considered for addressing drop-out among school leavers, although somewhat different issues arise at this point in the life-course. School leavers follow multiple potential paths, including joining the labour market, continuing in education, taking time out to travel, and more. These paths can involve geographic relocation, less time and availability for leisure activities, changes in personal perspective, and so on. For players who are not relocating and who already play their rugby with a local club, continuity of contact and involvement may be relatively straightforward. For the rest, however, including those who played the game only at school, among all the other changes occurring in their lives, making contact with a new rugby team is required if participation is to continue. Understood like this, it would perhaps not be surprising if a substantial proportion who would actually like to continue playing rugby nevertheless drop out.

This raises a number of questions: Do teachers who run school teams have incentives to put young players who are leaving school in touch with local clubs? Can systems be put in place to contact players at the end of their final school season in order to link them to relevant clubs and college teams? Can data systems be established to allow proactive contact with young players at the start of the season after they leave school? Most straightforwardly, can those responsible for the development of rugby in 
Ireland find ways to communicate with young players before and after they leave school, in order to make it easy and attractive for them to continue playing the game in the season that follows? The life-course of playing rugby (Figure 2.2) indicates that, in the context of increasing overall participation in rugby, this may be the single biggest challenge to be overcome.

Not far behind is the need to broaden rugby's appeal. As referred to above, there has been considerable progress in the promotion of women's rugby in recent years, but the data contained in this report imply that there is much further to go. Across the board, one-third of spectators at rugby matches are female. The proportion of girls in the children's game greatly outstrips the proportion of women in the adult game. Thus, there is clear scope for further expansion of women's rugby. The higher profile of the women's national team may have raised the profile of the women's game and, building also on the 2017 Women's World Cup, there is a favourable climate for promoting female participation. The data reported here (and more generally in relation to participation in sport) also reveal a role for parents in supporting and introducing children to the sport, such that the increased involvement of women in rugby is likely to have beneficial knockon effects for the next generation of players, both male and female.

To some extent, the socio-economic profile of rugby doubtless reflects its heritage and tradition. But the broader socio-economic spectrum of rugby players that exists in Munster is proof, if it were needed, that there is nothing intrinsic to the game that makes it attractive only to the better-off in society. The higher participation in Munster suggests that reaching out to a wider range of socio-economic groups elsewhere could raise overall participation; the implication is untapped demand for the game in communities not traditionally exposed to rugby. This insight offers empirical support to efforts by the provincial sides to raise the profile of the game in areas of their provinces where rugby is less popular, but it also indicates that more could be done, perhaps especially during times when the provincial and national sides are successful. Thus, there may be a return to devoting more resources to the strategic development of clubs and the staging of rugby events in targeted areas that contain families from lower socio-economic groups and where rugby is not traditionally strong.

Finally, rugby exists in a sporting context that has changed in recent years. The data show that, compared to previous generations, current young adults place a greater emphasis on, and have a better understanding of, the importance of physical activity for their health and wellbeing. More 
individuals are continuing to participate in sport and exercise as they progress through adulthood, making the transition from contact team sports to non-contact individual sports and exercise activities. Most adults in Ireland express the desire to do more physical activity. A modern rugby club that seeks to attract people of both sexes, to keep them as members over decades and, hopefully, to engage them as spectators and volunteers, might do well to capitalise on these trends. The present findings show that while many rugby players remain members of clubs once they cease to play the game, a large number do not. Clubs might therefore consider the benefits of organising opportunities for physical activity for members after they retire from the full game, whether through touch or tag rugby or other popular physical activities such as fitness classes, walking, cycling and golf. The result might be more active members who are also more engaged and involved in their rugby club and, therefore, more likely to develop a lifelong attachment and to give something back to the sport in a voluntary capacity. 


\section{APPENDIX A}

\section{The link between participation in sport and public health}

The scientific literature linking physical activity to health outcomes is now so extensive that it is impossible to provide an overview. This appendix therefore highlights the findings of some reports and studies that have themselves attempted to summarise the results, along with some studies of specific relevance to Ireland. The bibliographies within these studies are helpful and extensive.

Arguably the most comprehensive summary is the report of the Physical Activity Guidelines Advisory Committee (2008) for the US Department of Health and Human Services, which concluded that:

Strong evidence demonstrates that, compared to less active persons, more active men and women have lower rates of allcause mortality, coronary heart disease, high blood pressure, stroke, type 2 diabetes, metabolic syndrome, colon cancer, breast cancer, and depression. Strong evidence also supports the conclusion that, compared to less active people, physically active adults and older adults exhibit a higher level of cardiorespiratory and muscular fitness, have a healthier body mass and composition, and a biomarker profile that is more favourable for preventing cardiovascular disease and type 2 diabetes and for enhancing bone health. Modest evidence indicates that physically active adults and older adults have better quality sleep and health-related quality of life. (p. A-3)

Lee et al. (2012) reach similar conclusions.

Of course, sport accounts for only a part of overall physical activity. A succinct yet thorough review of the definitional and measurement issues surrounding sport, exercise and physical activity, together with a summary of the evidence linking sport to improved health outcomes, can be found in Khan et al. (2012). A review of the psychological and social benefits of participation in sport (Eime et al., 2013) examined 11 studies of adults and 30 involving children and adolescents, finding good evidence that participation is positive for wellbeing.

In an Irish context, evidence linking participation in sport to improved health can be found in Fahey et al. (2004) and Lunn and Layte (2008). 


\section{APPENDIX B}

\section{Notes and references on data sources}

The data sources employed in the present report have been used extensively by researchers in other contexts. Consequently, more detailed accounts of the survey designs and data collection methods are available in previous publications. This appendix draws attention to some of the most significant of these, so that readers who may have a specific question in relation to any one of the data sources might be able to locate an answer.

The ISM survey was commissioned by the Irish Sports Council ${ }^{9}$ and undertaken on an annual basis by the ESRI between 2007 and 2009. The 2011 and subsequent waves of the survey have been undertaken by the market research company Ipsos MRBI. The original design of the survey and data collection method are discussed extensively in Lunn et al. (2009). For further information and discussion about the participation levels recorded the reader is also directed to Ipsos MRBI (n.d. a).

Details on the design and method employed for the 2010 SAPAS survey are to be found in Ipsos MRBI (n.d. b).

The SSPE of 2003 was commissioned by the Irish Sports Council and conducted by the ESRI. Information and background can be found in Fahey et al. (2004). An account of how the data were transformed to reconstruct historical patterns of participation is contained in Lunn and Layte (2008).

The 2010 CSPPA was commissioned by the Irish Sports Council and conducted by a team of researchers from Dublin City University, the University of Limerick and University College Cork. Further details can be found in Walsh et al. (2011) and in Lunn et al. (2012).

Lastly, the methodological details of the School Leavers' Survey (SLS) 2007 are described in Byrne et al. (2008). 


\section{APPENDIX C}

\section{Active participation models}

TABLE C1 DETERMINANTS OF RUGBY PARTICIPATION IN ROI: ALL (COEFFICIENTS)

\begin{tabular}{|c|c|c|c|}
\hline & Age controls & Full controls & Income controls \\
\hline \multicolumn{4}{|l|}{ Gender (Ref: Female) } \\
\hline \multirow[t]{2}{*}{ Male } & $1.858 * * *$ & $1.834 * * *$ & $1.820 * * *$ \\
\hline & $(0.134)$ & $(0.138)$ & $(0.138)$ \\
\hline \multicolumn{4}{|l|}{ Age (Ref: Age 35-39) } \\
\hline \multirow[t]{2}{*}{ Age $16-19$} & $2.500 * * *$ & $2.353^{* * *}$ & $2.323 * * *$ \\
\hline & $(0.241)$ & $(0.274)$ & $(0.276)$ \\
\hline \multirow[t]{2}{*}{ Age 20-24 } & $1.652 * * *$ & $1.494 * * *$ & $1.469 * * *$ \\
\hline & $(0.228)$ & $(0.261)$ & $(0.263)$ \\
\hline \multirow[t]{2}{*}{ Age $25-29$} & $1.532 * * *$ & $1.408 * * *$ & $1.397 * * *$ \\
\hline & $(0.224)$ & $(0.247)$ & $(0.248)$ \\
\hline \multirow[t]{2}{*}{ Age $30-34$} & $0.831 * * *$ & $0.768 * * *$ & $0.764 * * *$ \\
\hline & $(0.246)$ & $(0.251)$ & $(0.251)$ \\
\hline \multirow[t]{2}{*}{ Age $40-49$} & $-0.570 * *$ & $-0.568^{* *}$ & $-0.566 * *$ \\
\hline & $(0.258)$ & $(0.267)$ & $(0.267)$ \\
\hline \multirow[t]{2}{*}{ Age 50 plus } & $-2.108^{* * *}$ & $-1.923^{* * *}$ & $-1.910 * * *$ \\
\hline & $(0.451)$ & $(0.473)$ & $(0.474)$ \\
\hline \multicolumn{4}{|c|}{ Education (Ref: Lower secondary) } \\
\hline \multirow[t]{2}{*}{ Primary } & -1.414 & -1.327 & -1.277 \\
\hline & $(1.025)$ & $(1.027)$ & $(1.028)$ \\
\hline \multirow[t]{2}{*}{ Upper secondary } & -0.169 & -0.149 & -0.166 \\
\hline & $(0.251)$ & $(0.253)$ & $(0.254)$ \\
\hline \multirow[t]{2}{*}{ Further/Higher education } & $0.543^{* *}$ & $0.547^{* *}$ & $0.475^{* *}$ \\
\hline & $(0.229)$ & $(0.234)$ & $(0.236)$ \\
\hline \multirow[t]{2}{*}{ Student (currently) } & $0.426^{*}$ & $0.415^{*}$ & $0.416^{*}$ \\
\hline & $(0.233)$ & $(0.250)$ & $(0.251)$ \\
\hline \multirow[t]{2}{*}{ Education Unknown } & -0.119 & -0.113 & -0.154 \\
\hline & $(0.398)$ & $(0.401)$ & $(0.402)$ \\
\hline \multicolumn{4}{|l|}{ Survey quarter (Ref: Q4) } \\
\hline \multirow[t]{2}{*}{ Q1 } & 0.027 & 0.007 & 0.002 \\
\hline & $(0.148)$ & $(0.148)$ & (0.149) \\
\hline \multirow[t]{2}{*}{ Q2 } & -0.033 & -0.051 & -0.067 \\
\hline & $(0.151)$ & $(0.151)$ & $(0.152)$ \\
\hline \multirow[t]{2}{*}{ Q3 } & 0.021 & 0.014 & 0.006 \\
\hline & $(0.149)$ & $(0.149)$ & $(0.150)$ \\
\hline \multicolumn{4}{|l|}{ Survey year (Ref: 2007) } \\
\hline \multirow[t]{2}{*}{2008} & $0.466^{* *}$ & $0.492^{* *}$ & $0.483^{* *}$ \\
\hline & $(0.226)$ & $(0.227)$ & $(0.227)$ \\
\hline \multirow[t]{2}{*}{2009} & -0.065 & -0.013 & 0.026 \\
\hline & $(0.226)$ & $(0.227)$ & $(0.228)$ \\
\hline
\end{tabular}




\begin{tabular}{|c|c|c|c|}
\hline & Age controls & Full controls & Income controls \\
\hline \multirow[t]{2}{*}{2011} & $0.485 * *$ & $0.546 * *$ & $0.653 * * *$ \\
\hline & (0.204) & $(0.217)$ & $(0.233)$ \\
\hline \multirow[t]{2}{*}{2013} & $0.518 * * *$ & $0.596 * * *$ & $0.685^{* * *}$ \\
\hline & $(0.199)$ & $(0.212)$ & $(0.216)$ \\
\hline \multirow[t]{2}{*}{2015} & 0.291 & $0.414^{*}$ & $0.495 * *$ \\
\hline & $(0.201)$ & $(0.215)$ & $(0.217)$ \\
\hline \multirow[t]{2}{*}{2017} & 0.219 & $0.873 * * *$ & $0.861^{* *}$ \\
\hline & $(0.213)$ & $(0.337)$ & $(0.338)$ \\
\hline \multicolumn{4}{|c|}{ Marital status (Ref: Single) } \\
\hline \multirow[t]{2}{*}{ Married } & & $-0.440^{*}$ & $-0.498 * *$ \\
\hline & & $(0.233)$ & $(0.236)$ \\
\hline \multirow[t]{2}{*}{ Cohabits } & & -0.224 & -0.219 \\
\hline & & $(0.232)$ & $(0.234)$ \\
\hline \multirow[t]{2}{*}{ Separated/Divorced } & & -0.369 & -0.333 \\
\hline & & $(0.481)$ & $(0.482)$ \\
\hline \multirow[t]{2}{*}{ Unknown } & & $0.888^{*}$ & $0.921 *$ \\
\hline & & $(0.487)$ & $(0.488)$ \\
\hline \multicolumn{4}{|c|}{ Children (Ref: Non-children) } \\
\hline \multirow[t]{2}{*}{ Children Over 18} & & -0.165 & -0.172 \\
\hline & & $(0.348)$ & (0.349) \\
\hline \multirow[t]{2}{*}{ Children aged $10-18$} & & 0.123 & 0.143 \\
\hline & & $(0.348)$ & $(0.349)$ \\
\hline \multirow[t]{2}{*}{ Children aged $<10$} & & 0.095 & 0.129 \\
\hline & & $(0.225)$ & $(0.227)$ \\
\hline \multicolumn{4}{|l|}{ Location (Ref: City) } \\
\hline \multirow[t]{2}{*}{ Town } & & -0.161 & -0.142 \\
\hline & & $(0.130)$ & $(0.131)$ \\
\hline \multirow[t]{2}{*}{ Village } & & -0.117 & -0.099 \\
\hline & & $(0.147)$ & $(0.147)$ \\
\hline \multirow[t]{2}{*}{ Rural } & & -0.132 & -0.111 \\
\hline & & $(0.139)$ & $(0.140)$ \\
\hline \multicolumn{4}{|c|}{ Region (Ref: Connacht-Ulster): } \\
\hline \multirow[t]{2}{*}{ Leinster } & & 0.148 & 0.127 \\
\hline & & $(0.142)$ & $(0.142)$ \\
\hline \multirow[t]{2}{*}{ Munster } & & 0.219 & 0.205 \\
\hline & & $(0.152)$ & $(0.152)$ \\
\hline \multicolumn{4}{|c|}{ Economic Status (Ref: Employed): } \\
\hline \multirow[t]{2}{*}{ Self-employed } & & $0.560 * * *$ & $0.578 * * *$ \\
\hline & & $(0.207)$ & $(0.207)$ \\
\hline \multirow[t]{2}{*}{ Unemployed } & & -0.082 & 0.005 \\
\hline & & $(0.194)$ & $(0.198)$ \\
\hline \multirow[t]{2}{*}{ Sick/disabled } & & -0.430 & -0.320 \\
\hline & & $(0.721)$ & $(0.722)$ \\
\hline Home duties & & 0.100 & 0.154 \\
\hline & & $(0.435)$ & $(0.435)$ \\
\hline
\end{tabular}




\begin{tabular}{|c|c|c|c|}
\hline & Age controls & Full controls & Income controls \\
\hline \multirow[t]{2}{*}{ Economic status unknown } & & 1.186 & 1.311 \\
\hline & & $(1.062)$ & $(1.063)$ \\
\hline \multicolumn{4}{|l|}{ Car ownership (Ref: No) } \\
\hline \multirow[t]{2}{*}{ Yes } & & $0.584 * *$ & $0.490 *$ \\
\hline & & $(0.264)$ & $(0.266)$ \\
\hline \multicolumn{4}{|c|}{ Parents played sport (Ref: neither) } \\
\hline \multirow[t]{2}{*}{ Father only } & & -0.200 & -0.222 \\
\hline & & $(0.158)$ & $(0.158)$ \\
\hline \multirow{2}{*}{ Mother only } & & $-0.783 * *$ & $-0.779 * *$ \\
\hline & & $(0.358)$ & $(0.359)$ \\
\hline \multirow[t]{2}{*}{ Both parents } & & -0.152 & -0.166 \\
\hline & & $(0.135)$ & $(0.134)$ \\
\hline \multirow[t]{2}{*}{ Unknown } & & -0.198 & -0.159 \\
\hline & & $(0.358)$ & $(0.359)$ \\
\hline \multicolumn{4}{|l|}{ Income (Ref: €400-499) } \\
\hline \multirow{2}{*}{$<300$} & & & 0.224 \\
\hline & & & $(0.529)$ \\
\hline \multirow[t]{2}{*}{ 300-399 } & & & 0.469 \\
\hline & & & $(0.482)$ \\
\hline \multirow[t]{2}{*}{$500-749$} & & & $0.825 * *$ \\
\hline & & & $(0.392)$ \\
\hline \multirow[t]{2}{*}{ 750-899 } & & & 0.663 \\
\hline & & & $(0.407)$ \\
\hline \multirow[t]{2}{*}{$900-1249$} & & & 0.608 \\
\hline & & & $(0.401)$ \\
\hline \multirow[t]{2}{*}{1250 and above } & & & $1.103 * * *$ \\
\hline & & & $(0.380)$ \\
\hline \multirow[t]{2}{*}{ Unknown } & & & 0.224 \\
\hline & & & $(0.529)$ \\
\hline \multirow[t]{2}{*}{ Constant } & $-7.194 * * *$ & $-7.518^{* * *}$ & $-8.138 * * *$ \\
\hline & $(0.343)$ & $(0.469)$ & $(0.585)$ \\
\hline Observations & 45,724 & 44,145 & 44,145 \\
\hline Pseudo $R$-squared & 0.222 & 0.224 & 0.228 \\
\hline
\end{tabular}

Note: $\quad$ Standard errors in parentheses; ${ }^{* * *} p<0.01,{ }^{* *} p<0.05,{ }^{*} p<0.1$. Analysis based on individuals aged $16-$ 60. 


\section{APPENDIX D}

\section{Social participation models}

\section{TABLE D1 DETERMINANTS OF RUGBY MEMBERSHIP IN ROI: ALL (COEFFICIENTS)}

\begin{tabular}{|c|c|c|}
\hline & Full controls & Income controls \\
\hline \multicolumn{3}{|l|}{ Gender (Ref: Female) } \\
\hline \multirow[t]{2}{*}{ Male } & $1.814^{* * *}$ & $1.790 * * *$ \\
\hline & $(0.098)$ & $(0.098)$ \\
\hline \multicolumn{3}{|l|}{ Age (Ref: Age 25-29) } \\
\hline \multirow[t]{2}{*}{ Age $16-19$} & $1.666 * * *$ & $1.600 * * *$ \\
\hline & $(0.197)$ & (0.199) \\
\hline \multirow[t]{2}{*}{ Age 20-24 } & $1.092 * * *$ & $1.040 * * *$ \\
\hline & $(0.178)$ & $(0.180)$ \\
\hline \multirow[t]{2}{*}{ Age 25-29 } & $0.713 * * *$ & $0.687^{* * *}$ \\
\hline & $(0.170)$ & $(0.171)$ \\
\hline \multirow[t]{2}{*}{ Age 30-34 } & 0.199 & 0.202 \\
\hline & $(0.170)$ & $(0.170)$ \\
\hline \multirow{2}{*}{ Age 40-49 } & 0.106 & 0.110 \\
\hline & $(0.134)$ & $(0.135)$ \\
\hline \multirow{2}{*}{ Age 50+ } & -0.062 & -0.050 \\
\hline & $(0.160)$ & $(0.160)$ \\
\hline \multicolumn{3}{|c|}{ Education (Ref: Lower secondary) } \\
\hline \multirow[t]{2}{*}{ Primary } & $-0.791^{*}$ & -0.694 \\
\hline & $(0.475)$ & $(0.476)$ \\
\hline \multirow[t]{2}{*}{ Upper secondary } & $0.438 * *$ & $0.376 * *$ \\
\hline & $(0.175)$ & $(0.176)$ \\
\hline \multirow[t]{2}{*}{ Further/Higher education } & $0.954 * * *$ & $0.801 * * *$ \\
\hline & $(0.164)$ & $(0.166)$ \\
\hline \multirow[t]{2}{*}{ Student (currently) } & $0.649 * * *$ & $0.600 * * *$ \\
\hline & $(0.200)$ & $(0.200)$ \\
\hline \multirow[t]{2}{*}{ Unknown } & $0.539 * *$ & $0.446 *$ \\
\hline & $(0.258)$ & $(0.259)$ \\
\hline \multicolumn{3}{|l|}{ Marital status (Ref: Single) } \\
\hline \multirow[t]{2}{*}{ Married } & -0.061 & -0.177 \\
\hline & $(0.147)$ & $(0.150)$ \\
\hline \multirow[t]{2}{*}{ Cohabits } & -0.187 & -0.229 \\
\hline & $(0.179)$ & $(0.180)$ \\
\hline \multirow[t]{2}{*}{ Separated/divorced } & $-0.663 * *$ & $-0.651 * *$ \\
\hline & $(0.283)$ & $(0.284)$ \\
\hline \multirow[t]{2}{*}{ Unknown } & 0.549 & 0.590 \\
\hline & $(0.475)$ & $(0.475)$ \\
\hline \multicolumn{3}{|l|}{ Children (Ref: Non-children) } \\
\hline \multirow[t]{2}{*}{ Children over 18} & 0.182 & 0.175 \\
\hline & $(0.156)$ & $(0.157)$ \\
\hline
\end{tabular}




\begin{tabular}{|c|c|c|}
\hline & Full controls & Income controls \\
\hline \multirow[t]{2}{*}{ Children aged $10-18$} & $0.278^{*}$ & $0.293^{*}$ \\
\hline & $(0.164)$ & $(0.165)$ \\
\hline \multirow[t]{2}{*}{ Children aged $<10$} & $0.288^{* *}$ & $0.322^{* *}$ \\
\hline & $(0.142)$ & $(0.143)$ \\
\hline \multicolumn{3}{|l|}{ Location (Ref: City) } \\
\hline \multirow[t]{2}{*}{ Town } & $-0.213^{* *}$ & $-0.190 *$ \\
\hline & $(0.105)$ & $(0.105)$ \\
\hline \multirow[t]{2}{*}{ Village } & $-0.380 * * *$ & $-0.361 * * *$ \\
\hline & $(0.121)$ & $(0.121)$ \\
\hline \multirow[t]{2}{*}{ Rural } & $-0.251 * *$ & $-0.230 * *$ \\
\hline & $(0.112)$ & $(0.112)$ \\
\hline \multirow[t]{2}{*}{ Unknown } & -0.656 & -0.625 \\
\hline & $(0.591)$ & $(0.591)$ \\
\hline \multicolumn{3}{|l|}{ Region (Ref: Dublin): } \\
\hline \multirow[t]{2}{*}{ Rest of Leinster } & $0.336 * * *$ & $0.353 * * *$ \\
\hline & $(0.114)$ & $(0.114)$ \\
\hline \multirow[t]{2}{*}{ Munster } & $0.484^{* * *}$ & $0.516 * * *$ \\
\hline & $(0.102)$ & $(0.102)$ \\
\hline \multirow[t]{2}{*}{ Connacht, Cavan, Donegal and Monaghan } & 0.014 & 0.053 \\
\hline & $0.336 * * *$ & $0.353^{* * *}$ \\
\hline \multicolumn{3}{|l|}{ Economic Status (Ref: Employed): } \\
\hline \multirow[t]{2}{*}{ Self-employed } & $0.422 * * *$ & $0.441 * * *$ \\
\hline & $(0.113)$ & $(0.114)$ \\
\hline \multirow[t]{2}{*}{ Unemployed } & 0.213 & 0.298 \\
\hline & $(0.258)$ & $(0.259)$ \\
\hline \multirow[t]{2}{*}{ Sick/disabled } & $-0.352 * *$ & -0.223 \\
\hline & $(0.156)$ & (0.159) \\
\hline \multirow[t]{2}{*}{ Home duties } & -0.062 & 0.022 \\
\hline & $(0.228)$ & $(0.228)$ \\
\hline \multirow[t]{2}{*}{ Unknown } & $1.661 * * *$ & $1.767 * * *$ \\
\hline & $(0.611)$ & $(0.613)$ \\
\hline \multicolumn{3}{|l|}{ Car ownership (Ref: No) } \\
\hline \multirow[t]{2}{*}{ Yes } & $0.838^{* * *}$ & $0.727 * * *$ \\
\hline & $(0.238)$ & $(0.239)$ \\
\hline \multicolumn{3}{|l|}{ Parents played sport (Ref: Neither) } \\
\hline \multirow[t]{2}{*}{ Father only } & -0.060 & -0.085 \\
\hline & $(0.113)$ & $(0.113)$ \\
\hline \multirow[t]{2}{*}{ Mother only } & -0.159 & -0.153 \\
\hline & $(0.236)$ & $(0.236)$ \\
\hline \multirow[t]{2}{*}{ Both parents } & $-0.207^{* *}$ & $-0.218^{* *}$ \\
\hline & $(0.103)$ & $(0.102)$ \\
\hline \multirow[t]{2}{*}{ Unknown } & -0.252 & -0.183 \\
\hline & $(0.273)$ & $(0.274)$ \\
\hline \multicolumn{3}{|l|}{ Survey quarter (Ref: Q4) } \\
\hline Q1 & -0.039 & -0.054 \\
\hline
\end{tabular}




\begin{tabular}{|c|c|c|}
\hline & Full controls & Income controls \\
\hline & (0.109) & (0.109) \\
\hline \multirow[t]{2}{*}{ Q2 } & -0.036 & -0.052 \\
\hline & $(0.108)$ & $(0.108)$ \\
\hline \multirow[t]{2}{*}{ Q3 } & -0.068 & -0.072 \\
\hline & $(0.107)$ & $(0.107)$ \\
\hline \multicolumn{3}{|c|}{ Survey year (Ref: 2007) } \\
\hline \multirow[t]{2}{*}{2008} & $0.298^{*}$ & $0.279 *$ \\
\hline & $(0.160)$ & $(0.160)$ \\
\hline \multirow[t]{2}{*}{2009} & 0.086 & 0.128 \\
\hline & $(0.152)$ & $(0.153)$ \\
\hline \multirow[t]{2}{*}{2011} & $0.712 * * *$ & $0.838 * * *$ \\
\hline & $(0.156)$ & $(0.172)$ \\
\hline \multirow[t]{2}{*}{2013} & $0.730 * * *$ & $0.798 * * *$ \\
\hline & $(0.151)$ & $(0.153)$ \\
\hline \multirow[t]{2}{*}{2015} & $0.494 * * *$ & $0.552 * * *$ \\
\hline & $(0.157)$ & $(0.158)$ \\
\hline \multirow[t]{2}{*}{2017} & $1.238 * * *$ & $1.189 * * *$ \\
\hline & $(0.283)$ & $(0.283)$ \\
\hline \multicolumn{3}{|c|}{ Income (Ref: €400-499) } \\
\hline \multirow[t]{2}{*}{$<300$} & & -0.061 \\
\hline & & $(0.398)$ \\
\hline \multirow[t]{2}{*}{ 300-399 } & & 0.236 \\
\hline & & $(0.339)$ \\
\hline \multirow[t]{2}{*}{$500-749$} & & $0.502^{*}$ \\
\hline & & $(0.260)$ \\
\hline \multirow[t]{2}{*}{$750-899$} & & $0.467^{*}$ \\
\hline & & $(0.268)$ \\
\hline \multirow[t]{2}{*}{$900-1,249$} & & $0.806 * * *$ \\
\hline & & $(0.254)$ \\
\hline \multirow[t]{2}{*}{1,250 and above } & & $1.040 * * *$ \\
\hline & & $(0.247)$ \\
\hline \multirow[t]{2}{*}{ Unknown } & & $0.559 * *$ \\
\hline & & $(0.245)$ \\
\hline \multirow[t]{2}{*}{ Constant } & $-7.430 * * *$ & $-7.862 * * *$ \\
\hline & $(0.344)$ & (0.409) \\
\hline Observations & 44,423 & 44,423 \\
\hline Pseudo $R$-squared & 0.121 & 0.126 \\
\hline
\end{tabular}

Note: $\quad$ Standard errors in parentheses; ${ }^{* *} p<0.01,{ }^{* *} p<0.05,{ }^{*} p<0.1$. Analysis based on individuals aged $16-60$. 


\begin{tabular}{|c|c|c|}
\hline & Full controls & Income controls \\
\hline \multicolumn{3}{|l|}{ Gender (Ref: Female) } \\
\hline \multirow[t]{2}{*}{ Male } & $0.552 * * *$ & $0.521 * * *$ \\
\hline & $(0.070)$ & $(0.070)$ \\
\hline \multicolumn{3}{|l|}{ Age (Ref: Age 25-29) } \\
\hline \multirow[t]{2}{*}{ Age $16-19$} & 0.289 & 0.202 \\
\hline & $(0.220)$ & $(0.223)$ \\
\hline \multirow[t]{2}{*}{ Age $20-24$} & 0.141 & 0.068 \\
\hline & $(0.188)$ & $(0.191)$ \\
\hline \multirow[t]{2}{*}{ Age 25-29 } & -0.059 & -0.092 \\
\hline & $(0.175)$ & $(0.176)$ \\
\hline \multirow{2}{*}{ Age 30-34 } & -0.203 & -0.200 \\
\hline & $(0.158)$ & $(0.159)$ \\
\hline \multirow[t]{2}{*}{ Age 40-49 } & $0.389 * * *$ & $0.386 * * *$ \\
\hline & $(0.107)$ & $(0.107)$ \\
\hline \multirow[t]{2}{*}{ Age $50+$} & 0.091 & 0.091 \\
\hline & $(0.129)$ & $(0.129)$ \\
\hline \multicolumn{3}{|c|}{ Education (Ref: Lower secondary) } \\
\hline \multirow{2}{*}{ Primary } & -0.373 & -0.303 \\
\hline & $(0.388)$ & $(0.389)$ \\
\hline \multirow[t]{2}{*}{ Upper secondary } & $0.682 * * *$ & $0.600 * * *$ \\
\hline & $(0.172)$ & $(0.173)$ \\
\hline \multirow[t]{2}{*}{ Further/Higher education } & $1.163^{* * *}$ & $0.964 * * *$ \\
\hline & $(0.162)$ & $(0.164)$ \\
\hline \multirow[t]{2}{*}{ Student (currently) } & $1.180 * * *$ & $1.117 * * *$ \\
\hline & $(0.223)$ & $(0.224)$ \\
\hline \multirow[t]{2}{*}{ Education unknown } & $1.172 * * *$ & $1.048 * * *$ \\
\hline & $(0.224)$ & $(0.225)$ \\
\hline \multicolumn{3}{|l|}{ Marital status (Ref: Single) } \\
\hline \multirow[t]{2}{*}{ Married } & 0.170 & 0.024 \\
\hline & (0.129) & $(0.132)$ \\
\hline \multirow[t]{2}{*}{ Cohabits } & -0.095 & -0.181 \\
\hline & $(0.175)$ & $(0.176)$ \\
\hline \multirow[t]{2}{*}{ Separated/divorced } & -0.163 & -0.149 \\
\hline & $(0.196)$ & $(0.197)$ \\
\hline \multirow[t]{2}{*}{ Unknown } & $0.953 * *$ & $0.984 * *$ \\
\hline & $(0.431)$ & $(0.433)$ \\
\hline \multicolumn{3}{|c|}{ Children (Ref: Non-children) } \\
\hline \multirow[t]{2}{*}{ Children over 18} & 0.099 & 0.092 \\
\hline & $(0.127)$ & $(0.127)$ \\
\hline \multirow[t]{2}{*}{ Children aged 10-18 } & $0.458 * * *$ & $0.472 * * *$ \\
\hline & $(0.128)$ & $(0.129)$ \\
\hline \multirow[t]{2}{*}{ Children aged $<10$} & $0.252 * *$ & $0.280 * *$ \\
\hline & $(0.123)$ & $(0.124)$ \\
\hline
\end{tabular}




\section{Full controls}

Income controls

Location (Ref: City)

Town

\begin{tabular}{c|c}
\hline$-0.516 * * *$ & $-0.482 * * *$ \\
\hline$(0.099)$ & $(0.100)$ \\
$-0.360 * * *$ & $-0.333^{* * *}$ \\
$(0.107)$ & $(0.108)$ \\
$-0.561 * * *$ & $-0.529 * * *$ \\
$(0.107)$ & $(0.107)$ \\
0.367 & 0.400 \\
$(0.306)$ & $(0.307)$ \\
\hline
\end{tabular}

Region (Ref Dublin):

Rest of Leinster

$0.213^{* *} \quad 0.233^{* *}$

$(0.104$

(0.105)

Munster

$0.204^{* *}$

$0.244 * * *$

(0.093)

(0.093)

Connacht, Monaghan, Cavan, Donegal

$-0.335^{* * *}$

$-0.289 * *$

(0.126)

(0.126)

Economic status (Ref: Employed):

Self-employed

$0.253^{* *}$

$0.262^{* *}$

(0.104)

(0.105)

Retired

$-0.318$

$-0.231$

(0.244)

(0.245)

Unemployed

$-0.640 * * *$

$-0.489 * * *$

(0.179)

(0.181)

Sick/disabled

$-0.871 * *$

$-0.719 * *$

(0.341)

(0.343)

Home duties

0.084

0.170

(0.121)

(0.122)

Unknown

0.071

0.165

(1.015)

(1.015)

Car ownership (Ref: No)

Yes

\begin{tabular}{cc|}
0.290 & 0.195 \\
\hline$(0.186)$ & $(0.188)$
\end{tabular}

\section{Parents played sport (Ref: Neither)}

\begin{tabular}{|l|c|c|}
\hline Father only & $0.234^{* *}$ & $0.201^{* *}$ \\
\hline Mother only & $(0.102)$ & $(0.102)$ \\
& 0.194 & 0.200 \\
\hline Both parents & $(0.208)$ & $(0.209)$ \\
\hline Unknown & -0.093 & -0.100 \\
\hline Income (Ref: $€ 400-499)$ & $(0.098)$ & $(0.098)$ \\
\hline <300 & $-0.752^{* *}$ & $-0.660^{*}$ \\
\hline 300-399 & $(0.342)$ & $(0.343)$ \\
\hline
\end{tabular}




\begin{tabular}{|c|c|c|}
\hline & Full controls & Income controls \\
\hline & & $(0.285)$ \\
\hline \multirow[t]{2}{*}{$500-749$} & & 0.122 \\
\hline & & $(0.223)$ \\
\hline \multirow[t]{2}{*}{ 750-899 } & & 0.344 \\
\hline & & $(0.223)$ \\
\hline \multirow[t]{2}{*}{$900-1249$} & & $0.601 * * *$ \\
\hline & & $(0.212)$ \\
\hline \multirow[t]{2}{*}{1250 and above } & & $0.912 * * *$ \\
\hline & & $(0.206)$ \\
\hline \multirow[t]{2}{*}{ Unknown } & & 0.297 \\
\hline & & $(0.208)$ \\
\hline \multicolumn{3}{|c|}{ Survey quarter (Ref: Q4) } \\
\hline \multirow[t]{2}{*}{ Q1 } & $-0.196 * *$ & $-0.221 * *$ \\
\hline & $(0.094)$ & $(0.094)$ \\
\hline \multirow[t]{2}{*}{ Q2 } & $-0.555 * * *$ & $-0.574 * * *$ \\
\hline & $(0.102)$ & $(0.102)$ \\
\hline \multirow[t]{2}{*}{ Q3 } & $-0.806 * * *$ & $-0.812 * * *$ \\
\hline & $(0.108)$ & $(0.108)$ \\
\hline \multicolumn{3}{|c|}{ Survey year (Ref: 2007) } \\
\hline \multirow[t]{2}{*}{2008} & $0.358 * *$ & $0.333^{* *}$ \\
\hline & (0.145) & $(0.145)$ \\
\hline \multirow[t]{2}{*}{2009} & $0.258 *$ & $0.299 * *$ \\
\hline & $(0.140)$ & $(0.141)$ \\
\hline \multirow[t]{2}{*}{2011} & $0.843 * * *$ & $1.033 * * *$ \\
\hline & $(0.148)$ & $(0.168)$ \\
\hline \multirow[t]{2}{*}{2013} & $0.966 * * *$ & $1.041^{* * *}$ \\
\hline & $(0.140)$ & $(0.142)$ \\
\hline \multirow[t]{2}{*}{2015} & $0.550 * * *$ & $0.589 * * *$ \\
\hline & $(0.150)$ & $(0.151)$ \\
\hline \multirow[t]{2}{*}{2017} & $0.642 * * *$ & $0.578 * *$ \\
\hline & $(0.236)$ & $(0.236)$ \\
\hline \multirow[t]{2}{*}{ Constant } & $-5.664 * * *$ & $-5.849 * * *$ \\
\hline & $(0.287)$ & $(0.336)$ \\
\hline Observations & 45,724 & 45,724 \\
\hline Pseudo $R$-squared & 0.0629 & 0.0697 \\
\hline
\end{tabular}

Note: $\quad$ Standard errors in parentheses; ${ }^{* *} p<0.01,{ }^{* *} p<0.05,{ }^{*} p<0.1$. Analysis based on individuals aged 16-60. 



\section{REFERENCES}

Byrne, D., S. McCoy and D. Watson (2008), School Leavers' Survey report 2007, Dublin: The Economic and Social Research Institute and the Department of Education and Science.

Department of Health (2016). A healthy weight for Ireland: obesity policy and action plan 2016-2025, Dublin: Department of Health.

Eime, R.M., J.A. Young, J.T. Harvey, M.J. Charity and W.R. Payne (2013), 'A systematic review of the psychological and social benefits of participation in sport for children and adolescents: informing development of a conceptual model of health through sport', International Journal of Behavioral Nutrition and Physical Activity, Vol. 10 https://doi.org/10.1186/1479-5868-10-98

Fahey, T., R. Layte and B. Gannon (2004), Sports participation and health among adults in Ireland, Dublin: The Economic and Social Research Institute.

Khan, K.M, A.M. Thompson, S.N. Blair, J.F. Sallis, K.E. Powell, F.C Bull and A.E. Bauman (2012), 'Sport and exercise as contributors to the health of nations', The Lancet, Vol. 380, No. 9836, pp. 59-64.

Ipsos MRBI (n.d. ${ }^{10}$ a), The Northern Ireland Sport and Physical Activity Survey (SAPAS): a baseline report, http://www.sportni.net/sportni/wpcontent/uploads/2013/03/SAPASReport.pdf

Ipsos MRBI (n.d. b), Irish Sports Monitor 2011 annual report, https://www.sportireland.ie/Research/The_Irish_Sports_Monitor/The_Iri sh_Sports_Monitor_2011/ISM-2011.pdf

Lee, I.M., E.J. Shiroma, F. Lobelo, P. Puska, S.N. Blair, P.T. Katzmarzyk and the Lancet Physical Activity Series Working Group (2012), 'Effect of physical inactivity on major non-communicable diseases worldwide: an analysis of burden of disease and life expectancy', The Lancet, Vol. 380, No. 9838, pp. 219-229.

Lunn, P., E. Kelly and N. Fitzpatrick (2012). Keeping them in the game: taking up and dropping out of sport and exercise in Ireland, Dublin: The Economic and Social Research Institute/Irish Sports Council.

Lunn, P. and R. Layte (2008), Sporting lives: an analysis of a lifetime of Irish sport, Dublin: The Economic and Social Research Institute.

Physical Activity Guidelines Advisory Committee (2008). Physical Activity Guidelines Advisory Committee report, 2008, Washington, DC: US Department of Health and Human Services.

Tucker, R., M. Raftery and E. Verhagen (2016). 'Injury risk and a tackle ban in youth rugby union: reviewing the evidence and searching for targeted, effective 
interventions. A critical review', British Journal of Sports Medicine, Vol. 50, No. 15, pp. 921-925.

Walsh, J., D. Tannehill and C.B. Woods (2011). The Children's Sport Participation and Physical Activity Study (CSPPA) - Volunteer Study, Research Report No. 2, Dublin: School of Health and Human Performance, Dublin City University and the Irish Sports Council. 
Whitaker Square,

Sir John Rogerson's Quay, Dublin 2

Telephone +35318632000

Email admin@esri.ie

Web www.esri.ie

Twitter @ESRIDublin

ISBN 978-0-7070-0510-2 